REVISTA DE LA CEPAL 86 AGOSTO 2005

\section{La dotación de capital humano de América Latina y el Caribe}

\author{
Gregorio Giménez
}

1

unque los trabajos teóricos y empíricos que emplean el concepto de capital humano son muy numerosos, no hay una definición generalmente aceptada de él, y en muchos casos se le identifica con educación formal. En estas páginas se precisará el concepto de capital humano, atendiendo a sus vías de adquisición. Además, en ellas se elabora un indicador internacional que recoge todos los matices que contempla la definición planteada y que, habitualmente, son dejados de lado por los indicadores tradicionales. Así, el indicador propuesto tendrá en cuenta la salud, la educación de tipo formal e informal y la experiencia. El análisis de las dotaciones de capital humano de los países de América Latina y el Caribe pone de manifiesto una situación de atraso con respecto a otras regiones. Sin embargo, cabe precisar que existen grandes diferencias entre países, que se han reducido en las últimas décadas gracias a un proceso de convergencia regional. 


\section{I}

\section{Introducción}

Desde muy diversas disciplinas - como la ciencia política, la filosofía o la sociología-, siempre se ha concedido gran importancia a la educación de los individuos, destacando el modo en que esta condicionaba el funcionamiento general de las sociedades. El impacto que tenía la educación fue resaltado también por la ciencia económica a partir del momento mismo de su nacimiento. Pese a todo, el interés por el estudio del capital humano encontró escaso eco entre los economistas hasta la década de 1960. Es en esa época cuando se empieza a publicar varios trabajos cruciales sobre el concepto de capital humano, como los de Becker (1962 y 1964), Schultz (1960, 1961 y 1962) o Denison (1962 y 1964).

De todas maneras, no será hasta la aparición de los nuevos modelos de crecimiento endógeno cuando empiece a darse en la literatura económica un creciente interés por el capital humano, al ver en él uno de los factores artífices del crecimiento. Algunos de los modelos más relevantes aparecen en Lucas (1988), Romer (1990), King y Rebelo (1990), Rebelo (1991), Stokey (1991), Young (1991), Lucas (1993) y Acemoglu (1997). En ellos, el capital humano permite aumentar la productividad del trabajo o actúa a través de la estimulación del cambio tecnológico. En cuanto a la evidencia empírica, entre los muchos trabajos recientes que constatan la conexión entre capital humano y crecimiento económico se encuentran los de Azariadis y Drazen (1990), Barro (1991), Levine y Renelt (1992), Mankiw, Romer, y Weil (1992), Kyriacou (1992), Barro y Lee (1994), Benhabib y Spiegel (1994 y 1997), de la Fuente y da Rocha (1996), Mingat y Tan (1996), Krueger y Lindahl (1999) o de la Fuente y Doménech (2001).

Además de constituir un destacado factor de crecimiento, el capital humano también tiene una extraordinaria importancia en otros muchos ámbitos. Así, como expresa la Organización para la Cooperación y el Desarrollo Económicos (OCDE, 1999), contribuye al desarrollo cultural e institucional, aumenta la cohesión social, posibilita la reducción de la delincuencia, favorece el interés por el cuidado del medioambiente, permite mejorar las condiciones de salubridad y refuerza la participación en la vida política, entre otras importantes contribuciones.

De la importancia que tiene el capital humano se desprende por qué será necesario que, tanto la definición del concepto como los indicadores construidos con el fin de cuantificarlo, recojan con la mayor precisión los elementos subyacentes. Precisamente, uno de los objetivos de estas páginas es ofrecer una definición de capital humano más elaborada que la que suele incorporar la mayoría de los trabajos que se encuentran en la literatura económica. Además, a partir de la definición propuesta, se construirán diferentes indicadores que nos aproximen a la medición de todos los matices que ella recoge, aglutinando posteriormente esta información en un único indicador. Sobre esta base, se procederá a realizar un análisis de la dotación de capital humano de América Latina y el Caribe, resaltando las diferencias intrarregionales e interregionales pero constatando un proceso de convergencia.

Así, el trabajo se estructura de la siguiente manera: después de esta introducción, en la sección II se profundiza en el concepto de capital humano y se ofrece una propuesta amplia de definición; en la sección III se construyen diversos indicadores basados en los diferentes elementos que entran en la definición planteada; en la sección IV se elabora un indicador global de capital humano y se evalúan sus propiedades con respecto al indicador tradicional de años medios de estudio; en la sección V se hace un diagnóstico de la situación en América Latina y el Caribe a partir del indicador de capital humano desarrollado, y finalmente, en la sección VI se ofrecen las conclusiones del trabajo. 


\section{II}

\section{El concepto de capital humano}

En esta sección se examina el concepto de capital humano en la literatura económica y se hace una propuesta amplia de definición, realizando una labor de síntesis $\mathrm{y}$ atendiendo a varios aspectos que se suele soslayar.

\section{Sobre el concepto de capital humano}

Las diferencias que nos separan a unos individuos de otros son observables en muchos terrenos, incluyendo el económico. Como consecuencia, la fuerza de trabajo no será homogénea. Esto es, las personas desarrollarán diferentes actividades con distinto grado de eficiencia, de forma que los trabajadores se distinguirán por las diferencias de productividad en la realización de tareas similares. La adecuación de cada trabajador para adaptarse a las necesidades del mercado de trabajo dependerá de las habilidades que posea. El capital humano determinará, pues, la capacidad que un individuo tiene para realizar un trabajo. Obsérvese que se adopta una perspectiva marcadamente económica, distinguiéndose el concepto de capital humano del concepto tradicional de educación, que tiene un matiz más social.

La idea subyacente en el concepto de capital humano no es nueva. Hace más de 200 años, en 1776, Adam Smith reconoció la importancia de las habilidades personales en la determinación de la riqueza de los individuos y las naciones (Smith, 1904). Sin embargo, el concepto formal de capital humano no fue desarrollado hasta la década de 1960. Así, en torno a dicho concepto pueden destacarse los trabajos de Schultz (1961) y Becker (1964). En ellos el capital humano se relaciona con la productividad y es definido como la suma de las inversiones en educación, formación en el trabajo, emigración o salud que tienen como consecuencia un aumento en la productividad de los trabajadores. El objeto de dichos trabajos es concebir la formación de los individuos como un proceso de inversión en el que la mayor capacitación se traducirá en mayor productividad y, en consecuencia, en mayores salarios. Así, la denominación de capital humano se explica por el hecho de tratarse de una modalidad de capital incorporado a las propias personas. El hecho de asociar el concepto de capital a los seres humanos creó una gran polémica entre los economistas de la época, pero pese a las críticas surgidas inicialmente, el capital humano pronto se perfiló como uno de los conceptos económicos más importantes de la segunda mitad del siglo XX.

Más recientemente, se ha ampliado el concepto primigenio con el fin de incluir tanto el trabajo remunerado como el realizado fuera del mercado, considerando el trabajo voluntario, el comunitario y el doméstico: así, se hace referencia a todas las actividades que directa o indirectamente crean renta o riqueza. Aun así, los economistas han empezado a reconocer que estas definiciones de capital humano son demasiado simples y dejan de lado aspectos cruciales, por lo que contribuyen poco al diseño de una adecuada política formativa. Laroche, Merette y Ruggeri (1999) sugieren que la definición tradicional de capital humano debería ampliarse para poder incluir el potencial de captación de capital humano, así como el capital poseído. En dicho trabajo, se define el capital humano como la suma de habilidades innatas y del conocimiento y destrezas que los individuos adquieren y desarrollan a lo largo de su vida (p.89, traducción del autor).

En esta misma línea, Ruggeri y Yu (2000) argumentan que el capital humano es un concepto dinámico y multifacético. Consideran que su análisis debería hacerse desde una perspectiva dinámica que cubra una amplia variedad de propósitos. De este modo, sugieren que el concepto de capital humano debería ampliarse para abarcar cuatro dimensiones: i) el potencial de capital humano, ii) la adquisición de capital humano, iii) la disponibilidad de dicho capital y iv) el uso efectivo del mismo. Así el concepto incorporaría la utilización y el rendimiento obtenido, reflejando, de algún modo, el lado de la demanda de capital humano.

En síntesis, tal y como señala Yu (2001), existen diferentes definiciones de capital humano en la literatura, aunque no hay una de general aceptación, y ello a pesar de que el capital humano es considerado uno de los factores productivos clave. El término capital humano ha sido tradicionalmente aplicado a la educación académica y solo recientemente se ha ampliado para incluir otra serie de aspectos. Las nuevas definiciones planteadas responden a las necesidades actuales de la economía y, al mismo tiempo, presentan nuevos retos para poder cuantificar el capital humano. 


\section{La definición de capital humano}

Sobre la base planteada, en este trabajo se elabora una definición de capital humano que incluye diversos elementos - algunos de ellos ya recogidos en la literatura anteriormente- y que se sustenta en las vías de adquisición y acumulación de capital humano. Para explicar la definición propuesta, se seguirá el esquema contenido en el gráfico 1.

De esta forma, se considera que el capital humano puede tener un origen innato o adquirido. El capital humano innato comprende aptitudes de tipo físico e intelectual, que pueden verse modificadas debido a las condiciones de alimentación y salud. El capital humano adquirido se irá constituyendo a lo largo de la vida de los sujetos, a través de la educación formal, de la educación informal y de la experiencia acumulada. Estos tres tipos de formación adquirida van a condicionar la instrucción laboral y el sistema de valores de los sujetos, que determinarán, junto a las aptitudes innatas, su rendimiento en el trabajo.

La instrucción laboral vendrá dada por los conocimientos obtenidos para desarrollar una determinada tarea. En muchos casos, un mismo tipo de formación podrá aplicarse a diversos trabajos. Por ejemplo, el aprendizaje del manejo de un ordenador personal constituirá una clase de conocimiento, adquirido en la escuela, el hogar o el entorno de trabajo, aprovechable para muy diferentes puestos laborales. Otras veces, un determinado tipo de instrucción laboral solo será útil para el desempeño de una función concreta, como, por ejemplo, la recibida para pilotar un avión. En este último caso, los empleados que poseen una formación específica son difícilmente sustituibles por otros, siendo necesario, en muchas ocasiones, incurrir en elevadas inversiones para dotar a los nuevos trabajadores de dichos conocimientos.

El sistema de valores de los individuos también tiene un origen adquirido. Estos valores van a ser un elemento clave de la capacidad laboral de los sujetos. Los empresarios les conceden una gran importancia, ya que de los valores poseídos dependerán la motivación, la fidelidad, la integridad, la diligencia o la constancia del trabajador a la hora de realizar su trabajo.

Una vez efectuada una primera aproximación a los elementos que conforman el capital humano, se va a

GRÁFICO 1

El concepto de capital humano

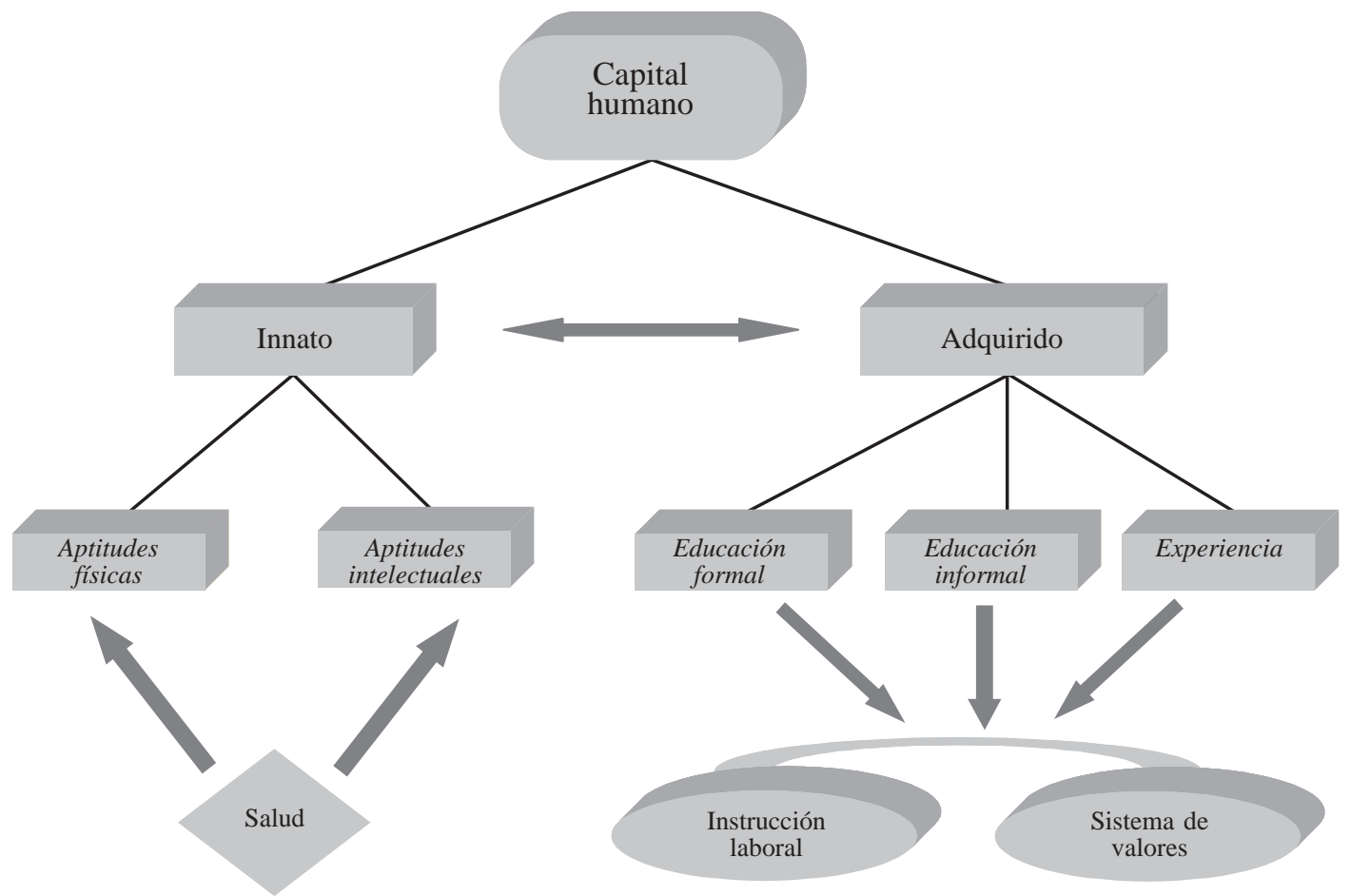

Fuente: Elaboración propia. 
proceder a estudiarlos con más detenimiento a lo largo de las páginas siguientes.

\section{a) Capital humano innato}

Ya desde el nacimiento, los seres humanos se distinguen por condicionantes genéticos, que van a provocar que posean diferentes aptitudes físicas e intelectuales y que determinarán la eficiencia en el desempeño de los trabajos que realizarán. Como aptitudes físicas se tendrán, entre otras, la fuerza, el sentido del equilibrio o la destreza manual; como aptitudes intelectuales la inteligencia, la atención o la concentración. Estas cualidades podrán ser cultivadas a lo largo de la vida a través del capital humano adquirido.

Aunque cada individuo posea características distintas, será lógico suponer que la media de individuos de un país va a tener las mismas cualidades de partida que la media de individuos de cualquier otro. Esto es, se considera que no existen diferencias de orden geográfico o racial. Ahora bien, aunque estas cualidades sean originariamente similares, su aprovechamiento estará supeditado a circunstancias relativas a las condiciones de salubridad del entorno donde habitan los sujetos. Así, la malnutrición o las inadecuadas condiciones de salud que afecten a un individuo podrán mermar las posibilidades que tiene de sacar partido a sus aptitudes innatas. ${ }^{1}$ Obsérvese que este modo de enfocar la influencia de la salud sobre la adquisición de capital humano difiere de los enfoques tradicionalmente adoptados. Así, en la mayoría de los trabajos se argumenta que una mejora en las condiciones de salud, medida a través de un aumento en la esperanza de vida, afectará al capital humano debido al aumento del período de vida activa de los individuos, que conllevará un incremento de la rentabilidad del capital humano. Este hecho se traducirá en un mayor crecimiento de las economías. La línea argumental explicada es la seguida por Meltzer (1995), Kalemli-Ozcan, Ryder y Weil (2000) —que, además, ofrecen un estudio empírico para el caso del Reino Unido-, y por Rodríguez y Sachs (1999) — que obtienen también resultados empíricos para el caso de Venezuela.

Sin embargo, hay que tomar con precaución el razonamiento expuesto. Esto porque, como se argu-

\footnotetext{
${ }^{1}$ Cuando apareció el concepto de capital humano, Schultz (1961) y Mushkin (1962) ya consideraron que las mejoras en las condiciones de salud podían aumentar las dotaciones de capital humano. Aun así, la salud ha sido dejada de lado por la gran mayoría de los trabajos teóricos y empíricos que consideraban el empleo de capital humano. Sobre salud y capital humano se hace un interesante análisis en Bandrés y García Delgado (2000).
}

menta en Echevarría (2004), los modelos planteados suponen un horizonte temporal infinito, sin tener en cuenta el período de jubilación. Sin embargo, resultará necesario considerar este factor para lograr una explicación correcta del proceso de inversión en capital humano. Los incrementos de la esperanza de vida no irán acompañados necesariamente de cambios en las decisiones de inversión en capital humano si no se producen cambios en el período de jubilación. Así, en la gran mayoría de países, la esperanza de vida supera actualmente la edad de jubilación. En el trabajo de Echevarría se ofrecen resultados empíricos para el caso de los Estados Unidos, que avalan este planteamiento. A todo esto hay que añadir que, en los países más pobres y con menor esperanza de vida, la inversión en capital humano está condicionada por otros factores mucho más importantes que el planteamiento del horizonte temporal de dicha inversión. Sirvan de ejemplo la necesidad de trabajar desde edades muy tempranas o la lejanía de los centros de formación. Los motivos expuestos avalarían el cambio de enfoque propuesto.

\section{b) Capital humano adquirido}

El capital humano adquirido comprende la educación formal e informal recibidas y la experiencia acumulada.

i) Educación formal. La educación formal incluye la educación infantil, primaria, secundaria y superior, constituyendo estos niveles académicos la base conceptual que se utiliza tradicionalmente para cuantificar el capital humano, bien a través de los años medios de estudio, del porcentaje de personas que han completado un determinado nivel de estudios o de los índices de matriculación en cada nivel de enseñanza. ${ }^{2}$ Parte de estos niveles académicos serán de realización obligatoria y parte voluntaria.

Además de la enseñanza académica reglada, la educación de tipo formal también incluirá la formación brindada a desempleados por parte de organismos públicos y los cursos de formación destinados a trabajadores que realizan las empresas y organismos públicos.

ii) Educación informal. El concepto de educación informal empezó a ser utilizado en pedagogía al final de la década de 1960 y principios de la de 1970 y abarca toda la formación recibida fuera de los ámbitos educativos institucionalizados. Así, la educación informal

\footnotetext{
${ }^{2}$ Véase en Barro y Lee (1993, 1996 y 2001) un análisis de los indicadores de educación académica formal y calidad de la educación.
} 
estará constituida por la instrucción que los sujetos reciban de la familia y su entorno social más próximo y por los conceptos asimilados a través del autoaprendizaje. $^{3}$

Por un lado, la familia y el círculo de relaciones siempre han constituido un pilar fundamental en la educación de los seres humanos. Por otro, cada vez adquiere más importancia la formación recibida por los sujetos a través de diversos medios de transmisión de información, y asimilada de manera individual. Entre estos vehículos de educación informal los libros han desempeñado, desde hace tiempo, un papel fundamental. Otros medios importantes de educación informal de aparición más reciente serían la prensa escrita, la televisión, la radio o Internet. ${ }^{4}$

iii) La experiencia. La experiencia está constituida por todas las vivencias acumuladas por un sujeto, que le permiten reaccionar ante las circunstancias basando su respuesta en los conocimientos previamente adquiridos. Dentro de la experiencia se puede distinguir la experiencia laboral, constituida por todos los conocimientos acumulados a través de la realización de una determinada tarea. La experiencia laboral es la más relevante desde una perspectiva económica, ya que constituye un factor determinante de la productividad de los trabajadores. ${ }^{5}$

\section{III}

\section{La medición del capital humano:}

\section{una nueva propuesta}

A lo largo de esta sección, se construirán diversos indicadores con el objeto de aproximarse a los diferentes aspectos incluidos en la definición planteada y que suelen ser dejados de lado por otros indicadores. Se concluirá con la elaboración de un único indicador que recoge los diferentes matices de la definición.

A partir del concepto de capital humano elaborado en la sección II, se plantearán aquí diversos indicadores que recogen todos los matices de la definición, esto es, que tienen en cuenta el capital humano innato, la educación formal, la educación informal y la experiencia acumulada. Sobre la base de estos

\footnotetext{
${ }^{3}$ Coombs, Prosser y Ahmed (1973, p. 23) definen la educación informal como el proceso realizado a lo largo del ciclo vital mediante el cual los individuos adquieren aptitudes, valores y conocimientos de la experiencia diaria y de los recursos e influencias educativas de su entorno más próximo, esto es, de la familia y de los vecinos, del trabajo y de los juegos, del mercado, de la biblioteca y de los medios de comunicación (traducción del autor). Tight (1996, p. 68) concede gran importancia a la educación recibida a través del aprendizaje y formación que tiene lugar fuera de instituciones formales (traducción del autor), distinguiéndola explícitamente de otros tipos de educación. La relevancia que este tipo de educación tiene en la formación de los individuos ha sido destacada por numerosos estudiosos de la educación; por ejemplo, Torres (1990) analiza su importancia en la política educativa implementada en países latinoamericanos, Foley (1999) se centra en el caso de experiencias desarrolladas en Australia, Brasil, Zimbabwe y los Estados Unidos y, por otra parte, Youngman (2000) destaca su trascendencia en la formación de adultos.
}

indicadores, se ha confeccionado un índice amplio de capital humano que se corresponde con el concepto barajado. Los diversos indicadores abarcan un período que va desde 1960 hasta la actualidad y comprenden la muestra de países más amplia posible en función de la información estadística disponible. A continuación se presentan los indicadores que recogen cada aspecto de la definición. ${ }^{6}$

\footnotetext{
${ }^{4}$ En el libro de Leadbeater (2000) se argumenta sobre la importancia que las nuevas tecnologías tienen en la adquisición de conocimientos.

${ }^{5}$ Sobre el aprendizaje mediante la práctica (learning by doing) y sus implicaciones sobre la productividad, véase Arrow (1962). En dicho trabajo se introduce esta noción, que implica que la experiencia derivada del uso de nuevas tecnologías durante el proceso productivo lleva aparejado un aumento de la eficiencia. De este modo, se produciría un incremento en la productividad de los trabajadores derivada de la experiencia, al menos hasta que entraran en juego los rendimientos decrecientes. Diversos modelos basados en el capital humano han resaltado el peso que el proceso de aprendizaje mediante la práctica tiene en el crecimiento, entre otros factores, debido al uso cada vez mayor de nuevas tecnologías. Algunos de estos modelos son los de Romer (1986), Stokey (1991), Young (1991), Parente (1994) y Greenwood y Yorukoglu (1997).

${ }^{6}$ Los datos referentes a educación formal provienen de Barro y Lee (2001). Las cifras sobre consumo de papel de uso cultural emanan del Instituto de Estadísticas de la Organización de las Naciones Unidas para la Educación, la Ciencia y la Cultura (UNESCO). El resto de los datos utilizados en la elaboración de los indicadores provienen de Indicadores del Desarrollo Mundial (Banco Mundial, varios años). Las estadísticas sobre uso de periódicos, radios, televisores y libros fueron completadas utilizando datos del Cross National
} 


\section{El capital humano innato}

Como ya se ha señalado, será lógico suponer que la media de individuos de un país va a tener las mismas cualidades innatas que la media de individuos de cualquier otro país. Ahora bien, el aprovechamiento de estas cualidades estará condicionado por circunstancias relativas a la situación de salubridad del entorno donde se desarrolla la vida de los sujetos. Así, partiendo de que las dotaciones de capital humano innato son las mismas para todos los países, se tratará de medir las consecuencias que las disparidades en las condiciones de salud tienen sobre el capital humano de origen innato. Esto se hace a través del indicador de esperanza de vida, que recoge información sobre la salud de todo el espectro poblacional y hace acopio de las consecuencias del conjunto de las condiciones de salubridad experimentadas por los individuos. Además, este indicador cuenta con un amplio número de observaciones temporales para un nutrido grupo de países.

\section{El capital humano adquirido}

El capital humano adquirido es el resultado de la educación formal e informal recibida y de la experiencia acumulada.

\section{a) Educación formal}

El mayor esfuerzo en la medición del capital humano a escala internacional se ha realizado recopilando información sobre educación formal. De entre todos los indicadores confeccionados, se va a optar por emplear la información acerca de los años medios de estudio elaborada por Barro y Lee (2001), ya que se ha construido utilizando el procedimiento más riguroso de cuantos estudios internacionales han sido realizados y proporciona información sobre el acervo de capital humano, frente a otros indicadores que captan flujos educativos. La fuente ofrece datos quinquenales desde 1960 hasta el 2000.

Hay que señalar que, desgraciadamente, la información internacional disponible sobre otros ámbitos de educación formal, como la formación brindada a

Time-Series Data Archive de Arthur S. Banks, extraído de la base de datos Social Indicators and Fixed Factors, del Banco Mundial. Todas las fuentes utilizadas presentan datos anuales desde 1960 hasta la actualidad para una muestra amplia de países. En los datos de Barro y Lee, la periodicidad es quinquenal. En las bases señaladas se puede obtener información más exhaustiva sobre las definiciones de las variables empleadas, así como sobre la disponibilidad de datos. desempleados y la formación a cargo de las empresas, es tan escasa que hace inviable su inclusión en un indicador internacional de capital humano.

\section{b) Educación informal}

La familia cumple un papel fundamental en la educación de los individuos, ${ }^{7}$ si bien no todas las familias van a ser capaces de brindar la misma atención a sus vástagos, ni van a disponer de los mismos recursos para educarlos. Esta circunstancia condicionará la formación que los hijos reciben en el seno de la unidad familiar. Por tal motivo, será necesario encontrar un indicador que permita cuantificar la atención y recursos que se dedican a la educación de los hijos, por término medio, en cada país. En este estudio se ha optado por utilizar la tasa de fecundidad como aproximación a la educación que los hijos pueden recibir de los padres. Así, esta tasa constituirá, en primer lugar, un indicador de la atención que los padres dedican a cada uno de los hijos. La atención disminuirá al aumentar el tamaño de la familia. En segundo lugar, el número de hijos limitará los recursos que se pueden dedicar a cada uno, puesto que habrá que repartir aquellos disponibles entre todos. A esto hay que añadir que la fecundidad está fuertemente correlacionada, de forma negativa, con el ingreso per cápita, lo que representa otra razón por la cual la tasa de fecundidad constituirá una aproximación a los recursos que cada familia puede dedicar a la formación de sus hijos. ${ }^{8}$

\footnotetext{
${ }^{7}$ Coombs y Ahmed (1974) argumentan que los ejemplos y actitudes que se observan dentro del entorno familiar van a constituir una parte esencial del proceso educativo.

${ }^{8}$ La disyuntiva establecida entre cantidad de hijos y calidad en su educación ha sido observada por Rosenzweig y Wolpin (1980), Behrman y Taubman (1986), y Hanushek (1992). Dichos trabajos apuntan a que el tamaño de la unidad familiar va a condicionar la inversión en la educación de los hijos, ya que cada hijo podrá recibir menos recursos. Esta idea ha sido recogida por diferentes modelos y trabajos empíricos. Así, Becker, Murphy y Tamura (1990) desarrollan un modelo que genera diferentes estados estacionarios de acuerdo a las relaciones que se establecen entre fecundidad, educación y crecimiento, apuntando a que los individuos deben elegir entre la cantidad y calidad de hijos que desean tener. Lam y Duryea (1999) encuentran un fuerte efecto negativo de la escolaridad femenina sobre la fecundidad y un fuerte efecto positivo de la escolaridad de los padres sobre la escolaridad de los hijos, argumentando que los efectos de la educación sobre la fecundidad se traducen, sobre todo, en una mayor inversión en la educación de los hijos y la mejora en la calidad de esa educación. En Moav (2005) se desarrolla un modelo basado en la fecundidad y la calidad de la educación, que ofrece una explicación de la persistencia en la situación de pobreza que experimentan algunos países; en dicho artículo se apunta a que la calidad de la educación que reciben los hijos está condicionada por la cantidad de hijos, suponiendo que la productividad de los progenitores en materia educativa se incrementa con
} 
Otro elemento importante de adquisición de educación informal es el autoaprendizaje a través de diferentes medios de transmisión de información. ${ }^{9}$ Con el fin de poder captar este factor determinante del capital humano adquirido, se ha elaborado para este trabajo un indicador de medios que posibilitan la adquisición de educación informal. A través de este indicador, tendremos una aproximación a diversas posibilidades de autoaprendizaje con las que cuentan los ciudadanos de cada país. Se pasa, seguidamente, a explicar cómo se ha confeccionado el índice de medios.
Se han examinado dos períodos de tiempo: uno está comprendido entre 1960 y 1989, el otro abarca la década de 1990. La metodología empleada en cada período es ligeramente distinta. El motivo ha sido la disponibilidad de datos existente en cada caso y la aparición de nuevos medios.

El índice de medios para 1960-1989 se ha confeccionado teniendo en cuenta el acceso de la población de cada país a libros, periódicos, radios y televisores. Es el siguiente:

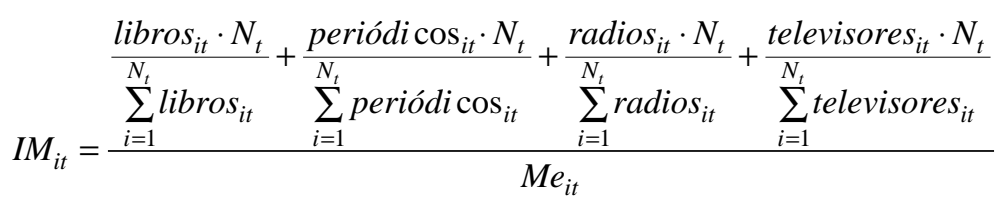

siendo:

$I M_{i t} \quad=$ índice de medios del país $i$ en el año $t$.

$i \quad=1,2, \ldots, N_{t} \quad$ Siendo $N_{t}$ el número de países de la muestra en el año $t$.

$t \quad=1960,1961, \ldots ., 1989$

libros $_{i t}=$ número de títulos de libros per cápita publicados en el país $i$ en el año $t$. Se incluyen todas las ediciones y los libros para niños y de texto. El dato hace referencia a títulos, no a volúmenes impresos.

En el índice de medios 1990-2000 se sustituye el número de títulos publicados por el consumo de papel para fines culturales, lo que ofrece una información más rica. Además, se incluye la utilización de periódicos $_{i t}=$ número de periódicos per cápita en circulación en el país $i$ en el año $t$. Solo se incluyen los periódicos diarios.

radios $_{i t}=$ número de aparatos de radio per cápita en el país $i$ en el año $t$.

televisores $_{i t}=$ número de aparatos de televisión per cápita en el país $i$ en el año $t$.

$M e_{i t}=$ medios analizados en el país $i$ en el año $t$.

ordenadores personales, que han revolucionado el acceso a la información en la última década a través de diversos programas y de Internet. El índice elaborado quedará como:

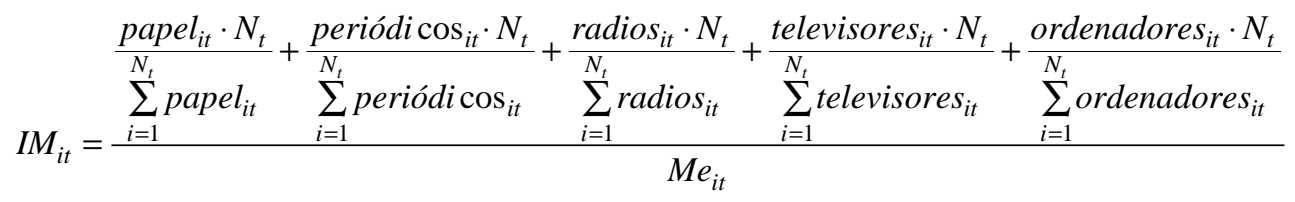

\footnotetext{
su propio grado de formación; como consecuencia, los países pobres tienen altas tasas de fecundidad y baja inversión en educación y, por ende, sus generaciones futuras también serán pobres. Del mismo modo, Tamura y Sadler (2001) construyen un modelo de generaciones traslapadas donde la fecundidad aparece como variable endógena que condiciona la educación que reciben los hijos. Hay que señalar, sin embargo, que la relación entre fecundidad y capital humano no solo se manifiesta en el sentido apuntado. Así, el capital humano también puede ser uno de los determinantes de la tasa de fecundidad, como indican Becker, Murphy y Tamura (1990) o Lam y Duryea (1999), si bien existen otros factores que influyen sobre la reducción de dicha tasa, como la disminución de la mortalidad, la expansión de los métodos anticonceptivos, el coste de oportunidad en términos salariales que representa cuidar a los hijos, o la menor dependencia de las personas ancianas.
}

\footnotetext{
${ }^{9}$ Los ya comentados trabajos de Coombs, Prosser y Ahmed (1973) y de Leadbeater (2000) señalan la importancia de esta vía para adquirir educación informal. Un hecho que da cuenta de la trascendencia de estos medios de aprendizaje es que el Centro de Investigación e Innovación en la Enseñanza, organismo dependiente de la Organización de Cooperación y Desarrollo Económicos (OCDE), está desarrollando un amplio programa que pretende estudiar el impacto que las tecnologías de la información y la comunicación ejercen sobre la calidad de la educación. Ya han sido publicados varios estudios sobre el aprendizaje a través de Internet, las consecuencias de la brecha tecnológica entre países y el impacto dramático que las nuevas oportunidades tienen sobre el aprendizaje.
} 
donde:

$\begin{array}{ll}I M_{i t} & =\text { es el índice de medios del país } i \text { en el } \\ & \text { año } t .\end{array}$

$=1,2, \ldots ., N_{t} \quad$ Siendo $N_{t}$ el número de países de la muestra en el año $t$.

$t \quad=1990,1991, \ldots ., 2000$

papel $_{i t}=$ kilogramos de papel de uso cultural consumidos por cada mil habitantes en el país $i$ en el año $t$.

periódicos $_{i t}=$ número de periódicos en circulación por cada mil habitantes en el país $i$ en el año $t$. Solo se incluyen los periódicos diarios.

radios $_{i t}=$ número de aparatos de radio por cada mil habitantes en el país $i$ en el año $t$.

televisores $_{i t}=$ número de aparatos de televisión por cada mil habitantes en el país $i$ en el año $t$.

ordenadores $_{i t}=$ número de ordenadores personales por cada mil habitantes en el país $i$ en el año $t$.

$M e_{i t} \quad=$ medios analizados en el país $i$ en el año $t$.

Ahora bien, no todos los sujetos podrán aprovechar de la misma manera los medios de que se dispone. Para poder aproximarnos a la rentabilización de estos instrumentos, se considerará que solamente los habitantes alfabetizados podrán sacarles pleno partido, mientras que los analfabetos no obtendrán provecho alguno. Aunque esta medida puede resultar arbitraria, el índice de alfabetización de cada país constituye un buen indicador del grado de aprovechamiento de los medios educativos disponibles, con lo que, introduciendo esta corrección, nos aproximaremos más a la situación real. Así, el índice de utilización de medios quedará, finalmente, como:

$$
I U M_{i t}=I M_{i t} \cdot A L F_{i t}
$$

siendo:

$I U M_{i t}=$ índice de utilización de medios del país $i$ en el año $t$.

$I M_{i t}=$ índice de medios del país $i$ en el año $t$.

$A L F_{i t}=$ tasa de alfabetización del país $i$ en el año $t$.

\section{c) Experiencia}

Hay pocas tentativas de aproximación a la medición de la experiencia, debido a las dificultades que entraña captar mediante un indicador el conocimiento acumulado a través de las vivencias o la actividad laboral. Para la realización de este trabajo se ha optado por calcular el número de años que el ciudadano medio de cada país ha estado inserto en el mercado de trabajo. Sin embargo, habrá que tener cautela a la hora de interpretar los resultados obtenidos. El inconveniente estriba en que las funciones profesionales que realiza un individuo suelen cambiar a lo largo de su vida laboral. Además, los trabajos no son homogéneos, hay empleos para los cuales la experiencia es más importante que para otros y tarda más en adquirirse.

Los años medios de experiencia laboral, esto es, los años que un individuo ha estado dentro del mercado de trabajo, se han calculado a partir de la edad media de la población del país, y de aquí se ha sustraído la edad en la que el individuo medio empezó a trabajar. ${ }^{10}$ Se ha considerado que la edad mínima de inserción en el mercado laboral son los 16 años, de acuerdo con los convenios internacionales, aunque en algunos casos, por desgracia, esta edad puede ser considerablemente menor. Con el fin de recoger esta circunstancia, se han empleado también datos sobre el trabajo realizado por niños de entre 10 y 14 años. Por último, habrá que tener presente también la situación opuesta. Así, en varios países la edad de inserción en el mercado de trabajo es superior a los 16 años, ya que el individuo medio ha prolongado su etapa formativa más allá de la edad mínima para trabajar. Se ha procedido, pues, a realizar tal corrección en los países que estaban en esta situación en algún momento del período contemplado de 1960-2000; estos países son Australia, Canadá, los Estados Unidos, Noruega, Nueva Zelandia, la República de Corea, Suecia y Suiza.

De este modo, se tendrá:

$$
E X P_{i t}=E M P_{i t}-E I M T_{i t}+A M T I_{i t}
$$

siendo:

$E X P_{i t}=$ indicador de experiencia laboral de un país $i$ en el año $t$.

$i \quad=1,2, \ldots, N_{t} \quad$ Siendo $N_{t}$ el número de países de la muestra en el año $t$.

$t \quad=1960,1961, \ldots ., 2000$

$E M P_{i t}=$ edad media de la población del país $i$ en el año $t$.

$E I M T_{i t}=$ edad media de incorporación al mercado de trabajo en el país $i$ en el año $t$.

$A M T I_{i t}=$ años medios que un habitante del país $i$ en el año $t$ ha estado realizando trabajo infantil.

\footnotetext{
10 También sería deseable atender al período medio durante el cual un trabajador arquetípico se ha encontrado en situación de desempleo; este dato no ha sido incorporado por no disponerse de suficiente información a escala internacional.
} 
Con todo, el indicador elaborado, aunque relativo al mercado de trabajo, no se debe relacionar únicamente con la experiencia laboral, sino que recogerá también la experiencia vital acumulada, que constituye una de las bases más importantes de conocimiento. Esto es debido a que la experiencia vital crecerá conforme aumenta la edad media de los individuos, que es el elemento clave en la elaboración del indicador.

En síntesis, siguiendo al concepto desarrollado inicialmente, el capital humano innato —que se considera, en promedio, igual para todos los individuospodrá verse alterado por las condiciones de salud, medidas a través de la esperanza de vida; la educación formal se plasmará mediante un indicador de años medios de estudio; la educación informal se recogerá a través de la tasa de fecundidad, que condensa las posibilidades de dedicar recursos y atención a la educación de los hijos, y la elaboración de un indicador de uso de medios de transmisión de información; por último, la experiencia acumulada se intentará aproximar mediante la confección de otro indicador, los años medios de inserción en el mercado de trabajo. Las tablas con los valores de los índices confeccionados se encuentran, bajo solicitud, a disposición de los interesados.

\section{IV}

\section{Elaboración de un indicador global de capital humano}

Una vez que se dispone de indicadores de los diferentes elementos que conforman el capital humano, se puede construir un indicador global que recoja todos los aspectos contemplados. El indicador se va a construir con una periodicidad quinquenal entre $1960 \mathrm{y}$ 2000. El motivo de no ofrecer una periodicidad anual es que, para su elaboración, se utilizan datos sobre educación formal obtenidos de Barro y Lee (2001), que tienen una periodicidad quinquenal, condicionando el período temporal analizado.

Con el propósito de evitar los efectos de escala, consecuencia de las diferentes definiciones y unidades que adoptan las variables, se ha procedido a tipificar éstas, restándole a cada dato la media muestral y dividiéndolo por su desviación típica. El procedimiento estadístico utilizado para construir el indicador es el análisis factorial. Concretamente, el método empleado será el de las componentes principales. Una cuestión importante es que, en todos los casos, una sola componente principal logra explicar más del $80 \%$ de la variación de las variables. Así pues, se podrá construir un indicador conjunto de capital humano que recoja el efecto de cada uno de los factores contemplados, condensándolo en un solo dato para cada país y año. ${ }^{11}$ Esto hará mucho más cómodo e intuitivo trabajar con los resultados obtenidos. Los indicadores de capital humano para cada uno de los años se encuentran en el apéndice al final del trabajo. La muestra total abarca 106 países para los que se dispone, en la gran mayoría de los casos, de información sobre un número muy elevado de períodos.

El indicador elaborado presenta la ventaja de recoger el efecto de los numerosos factores incluidos en la definición de capital humano, esto es, la salud, la educación formal e informal y la experiencia. Otros indicadores tradicionalmente utilizados se basaban en uno solo de estos aspectos. Por tanto, desde un punto de vista teórico, tendrá más sentido utilizarlo cuando se considere un concepto amplio de capital humano, frente al concepto más restrictivo de educación de tipo formal. Además, el período temporal que abarca es amplio y el índice se ha construido para una gran variedad de países, lo que facilita su uso en estudios de carácter empírico.

\footnotetext{
${ }^{11}$ Las ecuaciones obtenidas para cada período mediante el método de componentes principales son:

$\mathrm{H}_{60}=0,92 * \mathrm{ESV}_{60}+0,93 * \mathrm{AME}_{60}-0,93 * \mathrm{FEC}_{60}+0,85 * \mathrm{IUM}_{60}+0,92 * \mathrm{EXP}_{60}$ $\mathrm{H}_{65}=0,90 * \mathrm{ESV}_{65}+0,94 * \mathrm{AME}_{65}-0,94 * \mathrm{FEC}_{65}+0,90 * \mathrm{IUM}_{65}+0,91 * \mathrm{EXP}_{65}$ $\mathrm{H}_{70}=0,90 * \mathrm{ESV}_{70}+0,94 * \mathrm{AME}_{70}-0,95 * \mathrm{FEC}_{70}+0,91 * \mathrm{IUM}_{70}+0,91 * \mathrm{EXP}_{70}$ $\mathrm{H}_{75}=0,90 * \mathrm{ESV}_{75}+0,95 * \mathrm{AME}_{75}-0,96 * \mathrm{FEC}_{75}+0,91 * \mathrm{IUM}_{75}+0,92 * \mathrm{EXP}_{75}$ $\mathrm{H}_{80}=0,88 * \mathrm{ESV}_{80}+0,94 * \mathrm{AME}_{80}-0,94 * \mathrm{FEC}_{80}+0,91 * \mathrm{IUM}_{80}+0,94 * \mathrm{EXP}_{80}$ $\mathrm{H}_{85}=0,91 * \mathrm{ESV}_{85}+0,95 * \mathrm{AME}_{85}-0,95 * \mathrm{FEC}_{85}+0,92 * \mathrm{IUM}_{85}+0,94 * \mathrm{EXP}_{85}$ $\mathrm{H}_{90}=0,91 * \mathrm{ESV}_{90}^{85}+0,94 * \mathrm{AME}_{90}-0,94 * \mathrm{FEC}_{90}+0,87 * \mathrm{IUM}_{90}+0,94 * \mathrm{EXP}_{90}$ $\mathrm{H}_{95}=0,91 * \mathrm{ESV}_{95}+0,92 * \mathrm{AME}_{95}-0,93 * \mathrm{FEC}_{95}+0,86 * \mathrm{IUM}_{95}+0,93 * \mathrm{EXP}_{95}$ $\mathrm{H}_{00}=0,89 * \mathrm{ESV}_{00}+0,91 * \mathrm{AME}_{00}-0,93 * \mathrm{FEC}_{00}+0,85 * \mathrm{IUM}_{00}+0,92 * \mathrm{EXP}_{00}$ donde $H$ es el indicador de capital humano construido, ESV la esperanza de vida, $A M E$ los años medios de estudio, $F E C$ el índice de fecundidad, IUM el índice de utilización de medios y EXP el indicador de experiencia.
} 
CUADRO 1

Conjunto de países de la muestra: Variaciones medias en los puestos que ocupan los países según los indicadores de capital humano

\begin{tabular}{|c|c|c|c|c|c|c|c|c|c|c|}
\hline Variación media en puestos (a) & 5 & 6 & 7 & 7 & 8 & 7 & 8 & 9 & 8 & 7 \\
\hline Número de países de la muestra (b) & 71 & 84 & 92 & 101 & 100 & 101 & 102 & 100 & 93 & 94 \\
\hline Cociente entre (a) y (b) & $8 \%$ & $8 \%$ & $8 \%$ & $7 \%$ & $8 \%$ & $7 \%$ & $8 \%$ & $9 \%$ & $9 \%$ & $8 \%$ \\
\hline
\end{tabular}

Fuente: Elaboración propia.

CUADRO 2

Conjunto de países de la muestra: Coeficientes de correlación entre los indicadores de capital humano y diversas variables, $2000^{a}$

\begin{tabular}{|c|c|c|c|}
\hline Variable & $\begin{array}{l}\text { Años medios } \\
\text { de estudio }\end{array}$ & $\begin{array}{l}\text { Indicador de } \\
\text { capital humano }\end{array}$ & $\begin{array}{c}\text { Número de } \\
\text { observaciones }\end{array}$ \\
\hline PIB por habitante en dólares, a paridad de poder adquisitivo & 0,43 & 0,48 & 81 \\
\hline Población que vive con menos de un dólar diario & $-0,51$ & $-0,61$ & 43 \\
\hline Probabilidad de vivir más de 65 años (hombres) & 0,57 & 0,54 & 82 \\
\hline Probabilidad de vivir más de 65 años (mujeres) & 0,59 & 0,76 & 82 \\
\hline Años vividos con mala salud (hombres) & $-0,29$ & $-0,31$ & 82 \\
\hline Años vividos con mala salud (mujeres) & $-0,48$ & $-0,63$ & 82 \\
\hline Tasa de mortalidad infantil (por cada 1.000 nacidos vivos) & $-0,35$ & $-0,85$ & 84 \\
\hline Tasa de mortalidad infantil de los niños menores de 5 años & & & \\
\hline (por cada 1.000 nacidos vivos) & $-0,40$ & $-0,91$ & 84 \\
\hline Mortalidad en el parto & $-0,33$ & $-0,47$ & 82 \\
\hline Tasa de fecundidad enre los 15 y 19 años de edad & $-0,61$ & $-0,42$ & 82 \\
\hline Uso de anticonceptivos & 0,59 & 0,93 & 49 \\
\hline Científicos e ingenieros dedicados al I+D por cada millón de habitantes & 0,99 & 0,65 & 55 \\
\hline Técnicos dedicados a $\mathrm{I}+\mathrm{D}^{\mathrm{b}}$ por cada millón de habitantes & 0,65 & 0,98 & 51 \\
\hline Gasto en I+D como $\%$ del PIB & 0,31 & 0,80 & 52 \\
\hline Artículos en revistas científicas y técnicas por 100.000 habitantes & 0,77 & 0,98 & 84 \\
\hline Solicitud de patentes de residentes por 100.000 habitantes & 0,89 & 0,82 & 66 \\
\hline Mujeres en puestos de decisión a nivel ministerial (\%) & 0,29 & 0,31 & 78 \\
\hline Riesgo país: Institutional Investor Credit Rating (Institutional Investor Inc.) & 0,34 & 0,57 & 80 \\
\hline Riego país: Euromoney Country Credit-worthiness Rating (Euromoney Publications) & 0,26 & 0,50 & 82 \\
\hline
\end{tabular}

Fuente: Elaboración propia a partir de datos de Indicadores del desarrollo mundial (Banco Mundial, varios años). Para una definición detallada de las variables puede consultarse dicha fuente. En los casos en los que no se dispone de datos para el 2000 se toma el año más cercano. Los indicadores de riesgo-país son más elevados cuando el riesgo es menor.

a Muestras de países homogéneas.

b $\mathrm{I}+\mathrm{D}=$ investigación y desarrollo.

No obstante, siendo evidente su justificación teórica —en virtud de su mejor correspondencia con el concepto-, se deberá constatar también que la medición del capital humano realizada a través del nuevo indicador difiere de la obtenida a través de otros indicadores tradicionales. Con este propósito, se ha procedido a comparar el indicador confeccionado con el que tradicionalmente se suele utilizar en los trabajos empíricos, esto es, los años medios de estudio de la población (AME). ${ }^{12}$ Dicha comparación revela dife-

12 Dato tomado de las series elaboradas por Barro y Lee (2001). rencias apreciables en los períodos analizados. De esta forma, aunque ambos ofrecen resultados homogéneos, si ordenamos los países en función de los valores alcanzados por los respectivos indicadores, se observa que existen cambios de posición estimables según el índice que se utilice. Estos cambios obedecen a la inclusión de medios para adquirir capital humano distintos de los vehículos de educación académica habituales, que constituyen solamente una vía más de formación. El cuadro 1 ofrece los valores absolutos de las diferencias entre el puesto que ocupa un país en materia de capital humano, atendiendo al indicador construido, y el puesto que ocupa atendiendo al indicador basado en los años medios de educación (AME). 
Así, la utilización del índice de capital humano revela un desplazamiento medio de siete puestos - variación de $8 \%$ en la lista-, en términos absolutos, con respecto a la posición del mismo país al usar los años medios de estudio. Si se consideran los grupos de países con alta dotación de capital humano y los de baja dotación, dichas variaciones no implican movimientos de países entre esos grupos, pero sí ponen de manifiesto un cambio en la posición relativa entre países con dotaciones semejantes.

Además de constatar las diferencias existentes en la cuantificación del capital humano en función de cada indicador, será también importante tener en cuenta las diferencias en su desempeño estadístico. Con este propósito, se atenderá a la relación estadística entre los índices y una serie de variables, indicativas de desarrollo económico y social, correlacionadas a priori con el capital humano. Para determinar las diferencias existentes entre los dos indicadores, en el cuadro 2 se muestran los coeficientes de correlación que existen entre éstos y las variables analizadas.

Aunque el sentido de la relación con las variables es el mismo, hay contrastes considerables en la magnitud del coeficiente de correlación según el indicador de que se trate. La diferencia media entre los coeficientes obtenidos con ambos indicadores para cada caso es de 22 puntos porcentuales. Esto constata las diferencias en el desempeño estadístico entre ambas medidas de capital humano. Cabe señalar que en 15 de los 19 casos el nuevo indicador presenta mayor correlación con las variables analizadas.

Por lo tanto, el indicador elaborado recoge un concepto más amplio de capital humano y difiere del indicador tradicional de AME en su desempeño estadístico. A continuación se utilizarán estas propiedades para analizar, bajo un nuevo prisma, las dotaciones de capital humano de los países de América Latina y el Caribe.

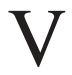

\section{Análisis espacial y temporal de las dotaciones de capital humano de América Latina y el Caribe}

El objetivo de esta sección es profundizar en el análisis espacial y dinámico de las dotaciones de capital humano sobre la base del indicador elaborado, lo que se hará en las dos subsecciones siguientes.

\section{Análisis espacial de las dotaciones de capital humano}

Con el fin de ofrecer un análisis comparativo de los distintos indicadores de capital humano de América Latina y el Caribe con respecto a otras regiones del planeta, se ha elaborado el cuadro 3 .

Este pone de manifiesto que las diferencias entre zonas geográficas son significativas y obedecen a disparidades, en conjunto, en los cinco indicadores básicos utilizados, aunque los contrastes adquieren especial relevancia en el caso de la educación formal e informal y son menores si se atiende a las diferencias en salud y experiencia.

América Latina y el Caribe posee dotaciones de capital humano superiores, en conjunto, a las del África subsahariana, las del sudeste de Asia, y las del Orien- te medio y norte de África. De hecho, se encuentra en una situación muy similar a esta última región, con unos índices de utilización de medios y de salud ligeramente inferiores $-52 \%$ y $106 \%$ del promedio mundial- pero con mejores dotaciones en educación formal recibida $-99 \%$ del promedio- $-\mathrm{y}$, sobre todo, una mayor experiencia - $94 \%$ del promedio- y mejores posibilidades de adquirir educación informal de origen familiar — de nuevo 94\% del promedio-. Por otro lado, las regiones del este de Asia y el Pacífico, de Europa del este y Asia central, de Europa occidental, y de América del Norte poseen, en conjunto, dotaciones superiores a las de América Latina y el Caribe en todos los aspectos barajados.

Ahora bien, a pesar del atraso relativo de la región de América Latina y el Caribe, un análisis pormenorizado de los países que la integran revela que entre ellos existen grandes diferencias. Así, del cuadro 4 se desprende que los países que poseen una mayor dotación de capital humano son, en este orden, Barbados, Uruguay, Chile, Trinidad y Tabago y Argentina. Estos países presentan valores del indicador global de 
CUADRO 3

Varias regiones: Análisis espacial de las dotaciones de capital humano, 2000

\begin{tabular}{|c|c|c|c|c|c|c|c|c|c|c|c|}
\hline & $\begin{array}{c}\text { Años } \\
\text { medios de } \\
\text { estudio }\end{array}$ & $\begin{array}{c}\text { Años } \\
\text { medios de } \\
\text { estudio/ } \\
\text { promedio } \\
\text { mundial }\end{array}$ & $\begin{array}{l}\text { Índice de } \\
\text { utilización } \\
\text { de medios }\end{array}$ & $\begin{array}{c}\text { Índice de } \\
\text { utilización } \\
\text { de medios/ } \\
\text { promedio } \\
\text { mundial }\end{array}$ & Salud & $\begin{array}{c}\text { Salud/ } \\
\text { promedio } \\
\text { mundial }\end{array}$ & $\begin{array}{l}\text { Expe- } \\
\text { riencia }\end{array}$ & $\begin{array}{c}\text { Experiencia/ } \\
\text { promedio } \\
\text { mundial }\end{array}$ & $\begin{array}{c}\text { Fecun- } \\
\text { didad }\end{array}$ & $\begin{array}{c}\text { Fecundidad/ } \\
\text { promedio } \\
\text { mundial }\end{array}$ & $\begin{array}{c}\text { Indicador } \\
\text { de capital } \\
\text { humano }\end{array}$ \\
\hline África subsahariana & 3,29 & 0,53 & 0,16 & 0,15 & 47,91 & 0,72 & 10,97 & 0,71 & 4,92 & 1,60 & $-4,57$ \\
\hline Sudeste de Asia & 3,38 & 0,54 & 0,08 & 0,08 & 61,21 & 0,92 & 12,99 & 0,85 & 3,99 & 1,29 & $-2,65$ \\
\hline América Latina y el Caribe & 6,13 & 0,99 & 0,52 & 0,52 & 70,81 & 1,06 & 14,52 & 0,94 & 2,89 & 0,94 & 0,19 \\
\hline Este de Asia y el Pacífico & 7,25 & 1,17 & 1,34 & 1,33 & 71,59 & 1,07 & 16,43 & 1,07 & 2,35 & 0,76 & 1,89 \\
\hline Europa del este y Asia central & 7,84 & 1,26 & 0,93 & 0,93 & 71,09 & 1,06 & 19,61 & 1,28 & 1,71 & 0,56 & 2,74 \\
\hline Europa occidental & 9,02 & 1,45 & 2,53 & 2,52 & 77,74 & 1,16 & 21,95 & 1,43 & 1,59 & 0,52 & 5,33 \\
\hline América del Norte & 11,84 & 1,91 & 3,71 & 3,70 & 77,97 & 1,17 & 18,57 & 1,21 & 1,80 & 0,58 & 6,30 \\
\hline Promedio de los países & 6,21 & 1,00 & 1,00 & 1,00 & 66,77 & 1,00 & 15,37 & 1,00 & 3,08 & 1,00 & 0,33 \\
\hline
\end{tabular}

Fuente: Elaboración propia.

CUADRO 4

América Latina y el Caribe: Análisis espacial de las dotaciones de capital humano, 2000

\begin{tabular}{|c|c|c|c|c|c|c|c|c|c|c|c|}
\hline & $\begin{array}{c}\text { Años } \\
\text { medios de } \\
\text { estudio }\end{array}$ & $\begin{array}{c}\text { Años } \\
\text { medios de } \\
\text { estudio/ } \\
\text { promedio } \\
\text { mundial }\end{array}$ & $\begin{array}{l}\text { Índice de } \\
\text { utilización } \\
\text { de medios }\end{array}$ & $\begin{array}{l}\text { Índice de } \\
\text { utilización } \\
\text { de medios/ } \\
\text { promedio } \\
\text { mundial }\end{array}$ & Salud & $\begin{array}{l}\text { Salud/ } \\
\text { promedio } \\
\text { mundial }\end{array}$ & $\begin{array}{l}\text { Expe- } \\
\text { riencia }\end{array}$ & $\begin{array}{c}\text { Experiencia/ } \\
\text { promedio } \\
\text { mundial }\end{array}$ & $\begin{array}{l}\text { Fecun- } \\
\text { didad }\end{array}$ & $\begin{array}{c}\text { Fecundidad/ } \\
\text { promedio } \\
\text { mundial }\end{array}$ & $\begin{array}{c}\text { Indicador } \\
\text { de capital } \\
\text { humano }\end{array}$ \\
\hline Argentina & 8,49 & 1,38 & 0,76 & 1,47 & 73,57 & 1,04 & 17,31 & 1,19 & 2,55 & 0,88 & 2,07 \\
\hline Barbados & 9,11 & 1,49 & 0,82 & 1,58 & 75,66 & 1,07 & 20,72 & 1,43 & 1,75 & 0,61 & 3,61 \\
\hline Brasil & 4,56 & 0,74 & 0,66 & 1,28 & 67,15 & 0,95 & 15,62 & 1,08 & 2,24 & 0,78 & 0,12 \\
\hline Colombia & 5,01 & 0,82 & 0,01 & 0,02 & 70,35 & 0,99 & 14,07 & 0,97 & 2,67 & 0,92 & $-0,53$ \\
\hline Costa Rica & 6,01 & 0,98 & 0,48 & 0,93 & 76,84 & 1,09 & 14,59 & 1,01 & 2,53 & 0,87 & 0,81 \\
\hline Chile & 7,89 & 1,29 & 1,68 & 3,24 & 75,51 & 1,07 & 16,35 & 1,13 & 2,19 & 0,76 & 2,72 \\
\hline Ecuador & 6,52 & 1,06 & 0,18 & 0,35 & 69,23 & 0,98 & 13,60 & 0,94 & 3,14 & 1,09 & $-0,38$ \\
\hline El Salvador & 4,50 & 0,73 & 0,42 & 0,81 & 69,53 & 0,98 & 13,66 & 0,94 & 3,20 & 1,11 & $-0,84$ \\
\hline Guatemala & 3,12 & 0,51 & 0,07 & 0,13 & 64,89 & 0,92 & 10,72 & 0,74 & 4,72 & 1,63 & $-3,34$ \\
\hline Honduras & 4,08 & 0,67 & 0,18 & 0,35 & 69,82 & 0,99 & 10,88 & 0,75 & 4,04 & 1,40 & $-2,16$ \\
\hline Jamaica & 5,22 & 0,85 & 0,45 & 0,87 & 75,16 & 1,06 & 15,29 & 1,05 & 2,54 & 0,88 & 0,54 \\
\hline México & 6,73 & 1,10 & 0,65 & 1,25 & 72,14 & 1,02 & 14,23 & 0,98 & 2,78 & 0,96 & 0,58 \\
\hline Nicaragua & 4,42 & 0,72 & 0,12 & 0,23 & 68,63 & 0,97 & 10,94 & 0,75 & 3,61 & 1,25 & $-1,93$ \\
\hline Panamá & 7,90 & 1,29 & 0,47 & 0,91 & 73,88 & 1,04 & 14,77 & 1,02 & 2,47 & 0,86 & 1,23 \\
\hline Paraguay & 5,74 & 0,94 & 0,40 & 0,77 & 69,95 & 0,99 & 11,50 & 0,79 & 4,03 & 1,39 & $-1,33$ \\
\hline Perú & 7,33 & 1,20 & 0,40 & 0,78 & 68,74 & 0,97 & 13,71 & 0,94 & 3,05 & 1,06 & 0,08 \\
\hline Trinidad y Tabago & 7,62 & 1,24 & 0,85 & 1,64 & 72,63 & 1,03 & 17,48 & 1,20 & 1,75 & 0,61 & 2,28 \\
\hline Uruguay & 7,25 & 1,18 & 1,41 & 2,73 & 74,30 & 1,05 & 19,16 & 1,32 & 2,26 & 0,78 & 2,75 \\
\hline Venezuela (República & & & & & & & & & & & \\
\hline Bolivariana de) & 5,61 & 0,92 & 0,41 & 0,79 & 73,16 & 1,03 & 13,53 & 0,93 & 2,88 & 0,99 & $-0,06$ \\
\hline $\begin{array}{l}\text { Promedio de los } \\
\text { países }\end{array}$ & 6,13 & 1,00 & 0,52 & 1,00 & 70,81 & 1,00 & 14,52 & 1,00 & 2,89 & 1,00 & 0,19 \\
\hline
\end{tabular}

Fuente: Elaboración propia. 
capital humano considerablemente superiores al promedio mundial, próximos a los de los grupos de países con una dotación de capital humano media alta.

Sin embargo, también nos encontramos con varios países que poseen una muy baja dotación de capital humano, con valores muy inferiores al promedio mundial, próximos a niveles de otras zonas del planeta con menor grado de desarrollo. La situación más grave dentro de la muestra de veintiún países corresponde a Guatemala, seguida de Honduras, Bolivia y Nicaragua. Los países con menores dotaciones de capital humano presentan deficiencias en todos los indicadores barajados, si bien estas son más acuciantes en el caso de la educación informal, medida a través del indicador de fecundidad y el índice de utilización de medios. Los países que se encuentran en peor situación atendiendo al primer indicador son Guatemala, Honduras y Bolivia. Estos mismos países también arrastran graves deficiencias reveladas por el índice de medios, llamando la atención, además, los casos de Colombia, Nicaragua y Ecuador, con cifras muy bajas en dicho índice.

Los indicadores de experiencia, salud y educación formal también revelan deficiencias, en general, en los países ya apuntados. Cabe destacar el déficit en educación formal que exhiben los países centroamericanos más atrasados. También es necesario resaltar este déficit formativo en el caso de Brasil, que si bien ha realizado un gran esfuerzo en este campo en los últimos años, todavía presenta cifras muy inferiores al promedio de países de la región.

En síntesis, América Latina y el Caribe experimenta un atraso relativo a nivel mundial y muestra importantes disparidades entre países. Algunos de estos presentan un déficit grave en el conjunto de indicadores analizados, lo que merma las posibilidades de convergencia con otras naciones más desarrolladas de la región, así como el despegue global de la región misma.

\section{Evolución de las dotaciones de capital humano}

Para observar la evolución de las dotaciones de capital humano en los países de América Latina y el Caribe se ha confeccionado el cuadro 5. En él aparecen los 17 países para los que se dispone de indicador de capital humano en todos los períodos quinquenales entre 1960 y 2000. El balance que arrojan los datos es positivo, puesto que un total de 12 países - Brasil, Chile, Colombia, Costa Rica, Ecuador, El Salvador, Honduras, México, Nicaragua, Panamá, Perú y Venezuela (República Bolivariana de)— han mejorado apreciablemente su situación relativa. En el caso de Chile, Costa Rica, El Salvador, México y Perú el esfuerzo realizado se ha traducido en avances notables. Merece también un inciso el caso de la República Bolivariana de Venezuela, que si bien ha experimentado una im-

CUADRO 5

América Latina: Evolución del indicador de capital humano, 1960-2000

\begin{tabular}{|c|c|c|c|c|c|c|c|c|c|}
\hline & 1960 & 1965 & 1970 & 1975 & 1980 & 1885 & 1990 & 1995 & 2000 \\
\hline Argentina & 3,77 & 3,92 & 4,07 & 3,16 & 2,78 & 2,71 & 2,42 & 2,29 & 2,07 \\
\hline Bolivia & $-2,02$ & $-2,25$ & $-2,64$ & $-2,61$ & $-2,49$ & $-2,31$ & $-2,02$ & $-2,07$ & $-2,08$ \\
\hline Brasil & $-1,31$ & $-1,17$ & $-0,84$ & $-0,70$ & $-0,61$ & $-0,28$ & $-0,18$ & $-0,05$ & 0,12 \\
\hline Colombia & $-1,71$ & $-1,68$ & $-1,27$ & $-0,46$ & $-0,33$ & 0,17 & $-0,30$ & $-0,38$ & $-0,53$ \\
\hline Costa Rica & $-1,35$ & $-0,95$ & $-0,09$ & 0,77 & 0,83 & 1,16 & 0,80 & 0,91 & 0,81 \\
\hline Chile & 0,67 & 0,79 & 1,40 & 1,69 & 2,15 & 2,33 & 2,24 & 2,32 & 2,72 \\
\hline Ecuador & $-1,73$ & $-1,77$ & $-1,74$ & $-1,36$ & $-0,79$ & $-0,36$ & $-0,26$ & $-0,30$ & $-0,38$ \\
\hline El Salvador & $-2,78$ & $-2,70$ & $-2,30$ & $-2,33$ & $-2,10$ & $-1,64$ & $-1,32$ & $-1,04$ & $-0,84$ \\
\hline Guatemala & $-3,35$ & $-3,26$ & $-3,18$ & $-3,27$ & $-3,34$ & $-3,60$ & $-3,45$ & $-3,46$ & $-3,34$ \\
\hline Honduras & $-3,56$ & $-3,60$ & $-3,58$ & $-3,31$ & $-3,25$ & $-2,34$ & $-2,26$ & $-2,24$ & $-2,16$ \\
\hline México & $-1,76$ & $-1,65$ & $-1,34$ & $-1,06$ & $-0,66$ & $-0,31$ & 0,37 & 0,55 & 0,58 \\
\hline Nicaragua & $-3,38$ & $-3,27$ & $-2,97$ & $-2,94$ & $-3,12$ & $-2,99$ & $-2,52$ & $-2,05$ & $-1,93$ \\
\hline Panamá & 0,06 & 0,35 & 0,28 & 0,55 & 0,97 & 1,35 & 1,47 & 1,31 & 1,23 \\
\hline Paraguay & $-0,47$ & $-0,77$ & $-0,59$ & $-0,60$ & $-0,79$ & $-1,10$ & $-1,02$ & $-1,28$ & $-1,33$ \\
\hline Perú & $-2,34$ & $-2,18$ & $-1,71$ & $-1,39$ & $-0,80$ & $-0,53$ & $-0,47$ & $-0,18$ & 0,08 \\
\hline Uruguay & 4,79 & 4,73 & 4,69 & 3,86 & 3,46 & 3,54 & 3,25 & 2,77 & 2,75 \\
\hline \multicolumn{10}{|l|}{ Venezuela (República } \\
\hline Bolivariana de) & $-1,40$ & $-1,13$ & $-0,73$ & $-0,22$ & 0,60 & 0,70 & 0,11 & 0,27 & $-0,06$ \\
\hline Promedio de los países & $-1,05$ & $-0,98$ & $-0,74$ & $-0,60$ & $-0,44$ & $-0,21$ & $-0,18$ & $-0,15$ & $-0,13$ \\
\hline
\end{tabular}

Fuente: Elaboración del autor. 
portante mejoría, que fue muy efectiva hasta la segunda mitad de la década de 1980, a partir de ahí comenzó un declive.

Dos países que se han estancado en la situación relativa de su capital humano con respecto al resto son Bolivia y Guatemala. Este hecho ha podido contribuir a ampliar la brecha en términos de desarrollo que separa a estas naciones del resto de países de la región.

Por último, existen tres naciones que han experimentado un deterioro paulatino en su situación relativa: Argentina, Paraguay y Uruguay, lo que ha llevado a una pérdida de competitividad del cono sur. Esto afecta negativamente al conjunto de la región, si bien de esta situación han podido sacar ventaja otros países de la zona, especialmente sus vecinos Brasil y Chile.

En todo caso, a pesar, del atraso relativo experimentado por Argentina, Paraguay y Uruguay, la región en su conjunto ha experimentado una mejora relativa en su posición mundial, tal y como se desprende de la evolución de la media del indicador para el conjunto de países. Esto se debe a que se han registrado valores crecientes en las dotaciones de capital humano reveladas por cada indicador. Cabe preguntarse ahora si este proceso de convergencia a escala mundial ha ido acompañado de una convergencia real a nivel regional. Con el fin de responder a esta pregunta, se han elaborado las funciones de densidad Kernel para 1960 y 2000, las que se presentan en el gráfico 2. Este procedimiento permite mostrar que hay convergencia entre las distintas naciones, sobre la base del índice de capital humano.

En 1960 existía una polarización más acentuada entre países con mayor y menor dotación de capital humano, que se refleja en el gráfico 2, donde se aprecian dos puntos máximos en la distribución. De esta manera, los países se dividían en dos grupos: uno, más numeroso, reunía a las naciones con una dotación más escasa, el otro, a las que poseían más capital humano. Esta polarización se fue reduciendo con el paso de los años, hasta llegar a una distribución más uniforme y más concentrada en el año 2000. Así, se puede concluir que la región ha experimentado un proceso de convergencia en dotaciones de capital humano.
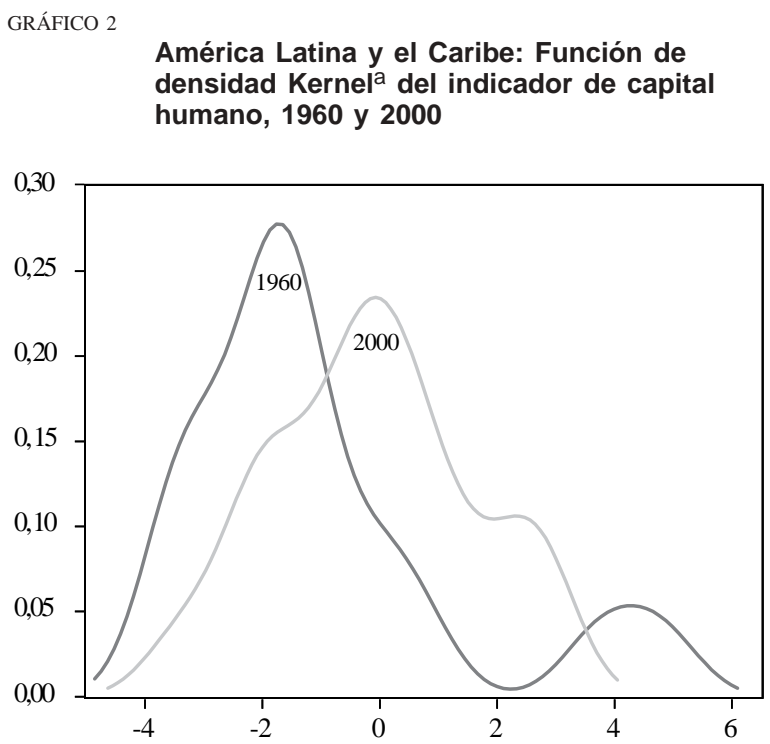

Fuente: Elaboración propia.

a La función de densidad Kernel permite alisar el histograma de la distribución estadística y lo transforma en un gráfico continuo, concediendo menos peso a las observaciones más alejadas del punto que está siendo evaluado. La densidad Kernel de una serie $\mathrm{X}$ en un determinado punto $\mathrm{x}$ se estima mediante la función:

$$
f(x)=\frac{1}{N \cdot h} \sum_{i=1}^{N} K\left(\frac{x-X_{i}}{h}\right)
$$

donde $N$ es el número de observaciones, $h$ el parámetro de alisado elegido y $K(x)$ la función Kernel empleada, de tipo gaussiano:

$$
\frac{1}{\sqrt{2 \pi}} \exp \left(-\frac{1}{2} u^{2}\right)
$$

donde $u$ es el argumento de dicha función Kernel.

El parámetro de alisado $h$ con el que se trabajará adoptará un valor de 0,65. Este parámetro se ha obtenido a partir de la aplicación del método propuesto por Silverman (1986, ecuación 3.31) a la serie de períodos con la que se trabaja. 


\section{VI}

\section{Conclusiones}

El capital humano tiene efectos trascendentales sobre la economía y la vida en sociedad, como lo han comprobado numerosos trabajos empíricos. Por lo tanto, es necesario que la definición de capital humano y los indicadores construidos para cuantificarlo recojan con la mayor precisión posible todos los elementos que incluye el concepto.

Así, en este trabajo se ha propuesto una definición amplia de capital humano, que distingue entre capital humano innato y adquirido. El capital humano innato comprende aptitudes de tipo físico e intelectual, que pueden verse modificadas debido a las condiciones de alimentación y salud. Dentro del capital humano adquirido se distingue entre la educación de tipo formal, la educación informal y la experiencia. La educación formal comprende la educación académica reglada, la formación impartida dentro de las empresas y los cursos a desempleados. La educación informal se transmitirá, fundamentalmente, en el círculo familiar, pero también podrá adquirirse mediante el autoaprendizaje realizado a través del uso de diferentes medios de transmisión de información, como los libros, los medios de comunicación o los ordenadores. La experiencia está constituida por todas las vivencias acumuladas por un sujeto, que le permiten reaccionar ante las circunstancias, basando su respuesta en los conocimientos adquiridos. Todos estos elementos condicionarán la instrucción laboral y el sistema de valores que poseen las personas, determinando de esta forma su productividad.

Una vez planteada la definición, se ha procedido a proponer diferentes indicadores que recojan cada elemento contemplado en ella.

- El capital humano innato, que se considera, en promedio, igual para todos los individuos, podrá verse alterado por las condiciones de salud, medidas a través de la esperanza de vida.

- La educación formal aparece plasmada mediante un indicador de años medios de estudio. No se dispone de información internacional consistente sobre otros tipos de educación formal.

- La educación informal se recoge mediante la tasa de fecundidad, que condensa las posibilidades de dedicar recursos y atención a la educación de los hijos, y un indicador de uso de medios de transmisión de información, a partir del uso de libros, periódicos, radios, televisores y ordenadores personales.

- Por último, la experiencia acumulada se aborda mediante la elaboración de otro indicador: los años medios de inserción en el mercado de trabajo.

Sobre la base de los indicadores anteriores y empleando el método de análisis de componentes principales, que permite la reducción de los datos, se ha elaborado un indicador global de capital humano para el período comprendido entre 1960 y 2000, ofreciendo datos quinquenales. La muestra de países recogida para cada período ronda la centena. Este indicador recoge más matices que los indicadores internacionales de capital humano con los que se trabaja habitualmente, fundamentados en la educación académica recibida.

El análisis de los países que integran la región de América Latina y el Caribe, a partir del indicador elaborado, pone de manifiesto que ésta se encuentra en una situación de atraso relativo respecto a las regiones del este de Asia y el Pacífico, Europa del este y Asia central, Europa occidental y América del Norte, si bien existen grandes diferencias en dotaciones de capital humano dentro del conjunto de los países latinoamericanos y caribeños.

Asimismo, a pesar del declive experimentado por Argentina, Paraguay y Uruguay en las cuatro últimas décadas, se constata que la región ha experimentado una mejoría relativa en su situación, así como un proceso de convergencia interna. Esto, sin duda, constituye una condición sine qua non para que se produzca una efectiva convergencia real a nivel intrarregional e interregional. 
APÉNDICE

Valores del indicador de capital humano

\begin{tabular}{|c|c|c|c|c|c|c|c|c|c|}
\hline & 1960 & 1965 & 1970 & 1975 & 1980 & 1985 & 1990 & 1995 & 2000 \\
\hline Afganistán & $-4,2$ & $-4,3$ & $-4,8$ & $-5,2$ & $-5,5$ & $-6,0$ & $-6,4$ & $-6,4$ & $-6,5$ \\
\hline Argelia & $\ldots$ & $-3,9$ & $-4,1$ & $-3,9$ & $-3,7$ & $-3,0$ & $-2,1$ & $-1,5$ & $-1,0$ \\
\hline Argentina & 3,8 & 3,9 & 4,1 & 3,2 & 2,8 & 2,7 & 2,4 & 2,3 & 2,1 \\
\hline Australia & 7,1 & 7,4 & 7,3 & 7,1 & 7,1 & 6,9 & 6,7 & 6,3 & 6,2 \\
\hline Austria & 6,8 & 6,8 & 6,6 & 6,5 & 6,8 & 6,9 & 6,6 & 5,5 & 5,7 \\
\hline Bahrein & $\ldots$ & $\ldots$ & $\ldots$ & $-1,6$ & $-0,5$ & 0,6 & 0,5 & 0,3 & 0,5 \\
\hline Bangladesh & $\ldots$ & $\ldots$ & $\ldots$ & $-4,3$ & $-4,2$ & $-4,1$ & $-3,4$ & $-3,0$ & $-2,7$ \\
\hline Barbados & $\ldots$ & $\ldots$ & 4,3 & 5,2 & 0,8 & 5,1 & 4,3 & 3,9 & 3,6 \\
\hline Bélgica & 7,4 & 7,4 & 7,2 & 6,8 & 6,3 & 6,4 & 6,5 & 5,8 & 5,4 \\
\hline Benín & $\ldots$ & $\ldots$ & $\ldots$ & $-4,6$ & $-4,9$ & $-5,4$ & $-5,5$ & $-5,4$ & $-5,3$ \\
\hline Bolivia & $-2,0$ & $-2,2$ & $-2,6$ & $-2,6$ & $-2,5$ & $-2,3$ & $-2,0$ & $-2,1$ & $-2,1$ \\
\hline Botswana & $\ldots$ & $\ldots$ & $-3,7$ & $-3,6$ & $-3,4$ & $-3,3$ & $-3,2$ & $-3,7$ & $-4,3$ \\
\hline Brasil & $-1,3$ & $-1,2$ & $-0,8$ & $-0,7$ & $-0,6$ & $-0,3$ & $-0,2$ & $-0,1$ & 0,1 \\
\hline Burundi & $\ldots$ & $\ldots$ & $\ldots$ & $\ldots$ & $\ldots$ & $\ldots$ & $-6,2$ & $\ldots$ & $\ldots$ \\
\hline Camerún & $-2,6$ & $-3,0$ & $-3,4$ & $-3,7$ & $-4,0$ & $-4,4$ & $-4,4$ & $-4,3$ & $-4,6$ \\
\hline Canadá & 7,0 & 6,5 & 7,0 & 7,5 & 8,1 & 8,1 & 6,9 & 6,7 & 6,3 \\
\hline Colombia & $-1,7$ & $-1,7$ & $-1,3$ & $-0,5$ & $-0,3$ & 0,2 & $-0,3$ & $-0,4$ & $-0,5$ \\
\hline Congo, Rep. Dem. & $-3,3$ & $-3,4$ & $-3,7$ & $-4,0$ & $-4,5$ & $-5,0$ & $-4,9$ & $-5,3$ & $-5,6$ \\
\hline Congo, Rep. & $\ldots$ & $\ldots$ & $\ldots$ & $\ldots$ & $\ldots$ & $\ldots$ & $-4,4$ & $-4,8$ & $-4,9$ \\
\hline Costa Rica & $-1,4$ & $-1,0$ & $-0,1$ & 0,8 & 0,8 & 1,2 & 0,8 & 0,9 & 0,8 \\
\hline Chipre & 2,8 & 3,3 & 3,8 & 4,8 & 5,0 & 4,4 & 3,7 & 3,2 & 3,4 \\
\hline Chile & 0,7 & 0,8 & 1,4 & 1,7 & 2,2 & 2,3 & 2,2 & 2,3 & 2,7 \\
\hline China & $\ldots$ & $\ldots$ & $\ldots$ & 0,3 & 0,6 & 0,9 & 2,9 & 2,0 & 1,6 \\
\hline Dinamarca & 8,6 & 8,8 & 8,3 & 8,0 & 7,8 & 7,8 & 7,2 & 6,4 & 5,8 \\
\hline República Dominicana & $-2,7$ & $-2,5$ & $-1,9$ & $-1,4$ & $-1,0$ & $-0,6$ & $-0,4$ & $-0,4$ & $\ldots$ \\
\hline Ecuador & $-1,7$ & $-1,8$ & $-1,7$ & $-1,4$ & $-0,8$ & $-0,4$ & $-0,3$ & $-0,3$ & $-0,4$ \\
\hline Egipto, Rep. Árabe de & $\ldots$ & $\ldots$ & $\ldots$ & $-2,5$ & $-2,5$ & $-2,2$ & $-1,7$ & $-1,4$ & $-1,1$ \\
\hline El Salvador & $-2,8$ & $-2,7$ & $-2,3$ & $-2,3$ & $-2,1$ & $-1,6$ & $-1,3$ & $-1,0$ & $-0,8$ \\
\hline Fiji & $\ldots$ & $\ldots$ & 0,5 & 1,1 & 1,3 & 1,4 & 0,9 & 0,8 & 1,4 \\
\hline Finlandia & 5,2 & 6,6 & 7,1 & 7,1 & 7,3 & 7,5 & 7,6 & 7,7 & 5,9 \\
\hline Francia & 6,1 & 6,2 & 6,1 & 6,0 & 5,8 & 6,0 & 5,8 & 5,6 & 5,0 \\
\hline Gambia & $\ldots$ & $\ldots$ & $\ldots$ & $-4,7$ & $-5,1$ & $-5,4$ & $-5,0$ & $-5,0$ & $-5,0$ \\
\hline Alemania & 8,2 & 8,2 & 7,7 & 7,2 & 7,2 & 7,1 & 7,0 & 6,5 & 5,9 \\
\hline Ghana & $-3,7$ & $-3,7$ & $-3,4$ & $-3,5$ & $-3,7$ & $-4,0$ & $-3,7$ & $-3,3$ & $-3,2$ \\
\hline Grecia & 4,7 & 4,7 & 4,5 & 4,7 & 4,7 & 5,0 & 4,8 & 4,8 & 4,7 \\
\hline Guatemala & $-3,3$ & $-3,3$ & $-3,2$ & $-3,3$ & $-3,3$ & $-3,6$ & $-3,4$ & $-3,5$ & $-3,3$ \\
\hline Guyana & $\ldots$ & $\ldots$ & $-1,2$ & $-0,2$ & $-0,1$ & 0,0 & 0,1 & 0,0 & $-0,1$ \\
\hline Haití & $-2,8$ & $-2,8$ & $-3,0$ & $-3,2$ & $-3,6$ & $-3,9$ & $-4,0$ & $-4,0$ & $\ldots$ \\
\hline Honduras & $-3,6$ & $-3,6$ & $-3,6$ & $-3,3$ & $-3,2$ & $-2,3$ & $-2,3$ & $-2,2$ & $-2,2$ \\
\hline Hong Kong, China & $\ldots$ & $\ldots$ & $\ldots$ & $\ldots$ & $\ldots$ & $\ldots$ & 6,0 & 6,3 & 5,5 \\
\hline Hungría & 6,2 & 6,7 & 6,8 & 6,3 & 5,8 & 5,6 & 4,4 & 4,0 & 3,9 \\
\hline Islandia & 6,2 & 7,3 & 7,6 & 7,7 & 7,7 & 5,6 & 4,7 & 4,8 & 4,7 \\
\hline India & $-2,7$ & $-2,6$ & $-2,4$ & $-2,3$ & $-2,3$ & $-2,2$ & $-1,8$ & $-1,5$ & $-1,4$ \\
\hline Indonesia & $-2,5$ & $-2,7$ & $-2,5$ & $-2,4$ & $-2,1$ & $-1,5$ & $-1,3$ & $-0,9$ & $-0,6$ \\
\hline Irán, Rep. Islámica del & $-3,4$ & $-3,4$ & $-3,2$ & $-3,1$ & $-3,3$ & $-3,2$ & $-2,3$ & $-1,3$ & $-0,5$ \\
\hline Iraq & $-3,8$ & $-3,8$ & $-3,6$ & $-3,3$ & $-3,2$ & $-3,3$ & $-3,5$ & $-3,5$ & $\ldots$ \\
\hline Irlanda & 4,8 & 4,7 & 4,3 & 4,1 & 3,9 & 4,3 & 4,4 & 4,5 & 4,7 \\
\hline Israel & 4,1 & 4,1 & 4,3 & 4,0 & 4,0 & 3,8 & 3,7 & 3,4 & 3,1 \\
\hline Italia & 5,3 & 5,2 & 5,1 & 4,6 & 4,4 & 4,5 & 5,3 & 5,0 & 4,8 \\
\hline Jamaica & $\ldots$ & $-0,3$ & $-0,1$ & 0,2 & 0,5 & 0,8 & 0,8 & 0,6 & 0,5 \\
\hline Japón & 6,0 & 7,0 & 6,9 & 6,6 & 6,8 & 6,7 & 7,4 & 7,2 & 6,4 \\
\hline Jordania & $\ldots$ & $\ldots$ & $\ldots$ & $\ldots$ & $\ldots$ & $-2,5$ & $-1,9$ & $-1,1$ & $-0,8$ \\
\hline Kenya & $\ldots$ & $-4,1$ & $-4,2$ & $-4,4$ & $-4,4$ & $-4,4$ & $-4,0$ & $-4,0$ & $-4,2$ \\
\hline Corea, Rep. de & $-1,0$ & $-0,2$ & 0,3 & 1,7 & 2,6 & 3,7 & $\ldots$ & $\ldots$ & $\ldots$ \\
\hline
\end{tabular}


Apéndice (continuación)

\begin{tabular}{|c|c|c|c|c|c|c|c|c|c|}
\hline & 1960 & 1965 & 1970 & 1975 & 1980 & 1985 & 1990 & 1995 & 2000 \\
\hline Kuwait & $\ldots$ & $-1,0$ & $-1,4$ & $-1,1$ & $-0,2$ & 0,6 & 0,9 & 0,8 & 0,9 \\
\hline Lesotho & $\ldots$ & $\ldots$ & $-2,1$ & $-2,3$ & $-2,5$ & $-2,8$ & $-2,8$ & $-3,5$ & $-4,2$ \\
\hline Liberia & $-3,3$ & $-3,5$ & $-3,8$ & $-4,0$ & $-4,3$ & $-4,8$ & $-6,0$ & $-6,1$ & $\ldots$ \\
\hline Malawi & $\ldots$ & $-3,9$ & $-4,5$ & $-4,7$ & $-5,1$ & $-5,5$ & $-5,8$ & $-6,1$ & $-6,6$ \\
\hline Malasia & $-2,2$ & $-1,8$ & $-1,2$ & $-0,4$ & 0,0 & 0,4 & 0,2 & 0,8 & 0,6 \\
\hline Malí & $-4,2$ & $-4,6$ & $-4,9$ & $-5,2$ & $-5,5$ & $-6,0$ & $\ldots$ & $-6,7$ & $-6,8$ \\
\hline Malta & $\ldots$ & 4,7 & 5,0 & 4,9 & 4,7 & 5,0 & $\ldots$ & $\ldots$ & $\ldots$ \\
\hline Mauritania & $\ldots$ & $\ldots$ & $\ldots$ & $\ldots$ & $\ldots$ & $\ldots$ & $-4,9$ & $\ldots$ & $\ldots$ \\
\hline Mauricio & $\ldots$ & $\ldots$ & 0,0 & 0,4 & 0,9 & 1,2 & 1,2 & 1,1 & 1,2 \\
\hline México & $-1,8$ & $-1,7$ & $-1,3$ & $-1,1$ & $-0,7$ & $-0,3$ & 0,4 & 0,5 & 0,6 \\
\hline Mozambique & $\ldots$ & $\ldots$ & $\ldots$ & $-4,5$ & $-4,9$ & $-5,7$ & $-6,1$ & $-6,1$ & $-6,0$ \\
\hline Myanmar & $-2,7$ & $-2,8$ & $-2,9$ & $-3,0$ & $-3,0$ & $-2,9$ & $-2,4$ & $-2,1$ & $-2,0$ \\
\hline Nepal & $-2,9$ & $-3,2$ & $-3,7$ & $-4,1$ & $-4,2$ & $-4,6$ & $-4,3$ & $-3,9$ & $-3,8$ \\
\hline Países Bajos & 5,9 & 6,2 & 6,7 & 7,0 & 6,7 & 6,7 & 6,5 & 5,9 & 5,6 \\
\hline Nueva Zelandia & 5,9 & 6,9 & 6,8 & 7,4 & 7,2 & 7,2 & 5,8 & 5,3 & 5,0 \\
\hline Nicaragua & $-3,4$ & $-3,3$ & $-3,0$ & $-2,9$ & $-3,1$ & $-3,0$ & $-2,5$ & $-2,0$ & $-1,9$ \\
\hline Níger & $-4,5$ & $-4,8$ & $-5,0$ & $-5,3$ & $-5,8$ & $-6,5$ & $-6,7$ & $-7,1$ & $-7,3$ \\
\hline Noruega & 6,7 & 7,1 & 7,5 & 7,4 & 7,0 & 7,2 & 6,9 & 6,8 & 6,5 \\
\hline Pakistán & $-3,6$ & $-3,8$ & $-3,7$ & $-3,8$ & $-4,0$ & $-4,1$ & $-3,8$ & $-3,8$ & $-3,7$ \\
\hline Panamá & 0,1 & 0,3 & 0,3 & 0,5 & 1,0 & 1,3 & 1,5 & 1,3 & 1,2 \\
\hline Papua Nueva Guinea & $\ldots$ & $\ldots$ & $\ldots$ & $-3,4$ & $-3,9$ & $-4,2$ & $-4,1$ & $-3,7$ & $-3,5$ \\
\hline Paraguay & $-0,5$ & $-0,8$ & $-0,6$ & $-0,6$ & $-0,8$ & $-1,1$ & $-1,0$ & $-1,3$ & $-1,3$ \\
\hline Perú & $-2,3$ & $-2,2$ & $-1,7$ & $-1,4$ & $-0,8$ & $-0,5$ & $-0,5$ & $-0,2$ & 0,1 \\
\hline Filipinas & $-1,7$ & $-1,4$ & $-1,2$ & $-0,8$ & $-0,8$ & $-0,7$ & $-0,3$ & $-0,2$ & $-0,2$ \\
\hline Polonia & 4,3 & 5,0 & 5,5 & 5,4 & 4,9 & 4,2 & 3,8 & 3,9 & 4,0 \\
\hline Portugal & 2,7 & 2,7 & 2,6 & 2,5 & 2,6 & 3,4 & 3,2 & 3,3 & 3,2 \\
\hline Rwanda & $\ldots$ & $\ldots$ & $-5,0$ & $-5,5$ & $-5,8$ & $-5,9$ & $-6,5$ & $-6,8$ & $\ldots$ \\
\hline Senegal & $-3,5$ & $-3,9$ & $-4,2$ & $-4,3$ & $-4,6$ & $-5,1$ & $-5,1$ & $-5,1$ & $-5,1$ \\
\hline Sierra Leona & $\ldots$ & $-4,3$ & $-4,7$ & $-5,2$ & $-5,6$ & $-6,3$ & $-6,8$ & $-7,1$ & $\ldots$ \\
\hline Singapur & $\ldots$ & $-0,4$ & 0,9 & 1,9 & 2,2 & 2,3 & 2,7 & 2,8 & 3,0 \\
\hline Sudáfrica & $-1,5$ & $-1,5$ & $-1,3$ & $-1,3$ & $-1,1$ & $-0,7$ & $-0,8$ & $-0,3$ & $-1,3$ \\
\hline España & 3,9 & 4,2 & 4,4 & 3,9 & 4,0 & 4,5 & 4,6 & 4,6 & 4,7 \\
\hline Sri Lanka & 0,0 & 0,2 & 0,3 & 0,2 & 0,7 & 0,9 & 0,8 & 0,9 & 1,0 \\
\hline Sudán & $-4,0$ & $-4,1$ & $-4,3$ & $-4,5$ & $-4,6$ & $-4,6$ & $-4,5$ & $-4,2$ & $-4,0$ \\
\hline Swazilandia & $\ldots$ & $\ldots$ & $-3,6$ & $-3,4$ & $-3,5$ & $-3,4$ & $-3,2$ & $-2,8$ & $\ldots$ \\
\hline Suecia & 9,4 & 9,3 & 8,8 & 8,7 & 8,2 & 8,2 & 7,2 & 7,1 & 7,8 \\
\hline Suiza & 7,5 & 7,4 & 7,7 & 8,0 & 8,1 & 8,0 & 7,4 & 6,9 & 6,5 \\
\hline República Árabe Siria & $\ldots$ & $-3,6$ & $-3,5$ & $-3,4$ & $-3,5$ & $-3,3$ & $-2,6$ & $-1,8$ & $-1,5$ \\
\hline Tailandia & $-1,5$ & $-1,6$ & $-1,3$ & $-1,0$ & $-0,3$ & 0,5 & 1,0 & 1,2 & 1,2 \\
\hline Togo & $-3,7$ & $-3,8$ & $-4,0$ & $-4,2$ & $-4,3$ & $-4,8$ & $-5,1$ & $-5,0$ & $-5,0$ \\
\hline Trinidad y Tabago & $\ldots$ & 1,1 & 1,5 & 1,5 & 2,5 & 2,5 & 2,1 & 2,0 & 2,3 \\
\hline Túnez & $-3,4$ & $-3,6$ & $-3,3$ & $-2,7$ & $-2,2$ & $-1,8$ & $-1,1$ & $-0,4$ & 0,0 \\
\hline Turquía & $-1,8$ & $-1,6$ & $-1,4$ & $-1,2$ & $-1,1$ & $-0,8$ & $-0,3$ & 0,1 & 0,4 \\
\hline Uganda & $\ldots$ & $-3,6$ & $-3,8$ & $-4,2$ & $-4,8$ & $-5,5$ & $-5,7$ & $-6,2$ & $-6,4$ \\
\hline Emiratos Árabes Unidos & $\ldots$ & $\ldots$ & $\ldots$ & $-0,5$ & $\ldots$ & $\ldots$ & $\ldots$ & $\ldots$ & $\ldots$ \\
\hline Reino Unido & 8,9 & 7,8 & 7,5 & 7,6 & 7,1 & 7,2 & 6,6 & 6,2 & 5,5 \\
\hline Estados Unidos & 8,9 & 8,8 & 8,7 & 9,2 & 9,4 & 9,5 & 8,0 & 7,0 & 6,3 \\
\hline Uruguay & 4,8 & 4,7 & 4,7 & 3,9 & 3,5 & 3,5 & 3,2 & 2,8 & 2,8 \\
\hline \multicolumn{10}{|l|}{ Venezuela (República } \\
\hline Bolivariana de) & $-1,4$ & $-1,1$ & $-0,7$ & $-0,2$ & 0,6 & 0,7 & 0,1 & 0,3 & $-0,1$ \\
\hline \multicolumn{10}{|l|}{ Yugoslavia, RF } \\
\hline (Serbia/Montenegro) & 3,7 & 4,0 & 4,2 & 4,1 & 3,7 & 3,4 & 3,0 & $\ldots$ & $\ldots$ \\
\hline Zambia & $\ldots$ & $-3,5$ & $-3,7$ & $-4,1$ & $-4,3$ & $-4,6$ & $-4,9$ & $-4,8$ & $-5,2$ \\
\hline Zimbabwe & $\ldots$ & $-3,7$ & $-3,7$ & $-3,6$ & $-3,5$ & $-3,5$ & $-3,0$ & $-3,5$ & $-3,7$ \\
\hline
\end{tabular}

Fuente: Elaboración propia. 
Acemoglu, D. (1997): Why Do New Technologies Complement Skills? Directed Technical Change and Wage Inequality, documento de trabajo, $\mathrm{N}^{\circ}$ 97-14, Cambridge, Massachusetts, Instituto de Tecnología de Massachusetts.

Arrow, K. (1962): The economic implications of learning by doing, The Review of Economic Studies, vol. 29, No 3, Oxford, Reino Unido, Instituto de Economía y Estadísticas, Universidad de Oxford.

Azariadis, C. y A. Drazen (1990): Threshold externalities in economic development, The Quarterly Journal of Economics, vol. 105, $\mathrm{N}^{\mathrm{O}}$ 2, Cambridge, Massachusetts, The MIT Press, mayo.

Bandrés, E. y J.L. García Delgado (2000): Estado de bienestar y crecimiento económico, en S. Muñoz Machado, J.L. García Delgado y L. González Seare (dirs.), Las estructuras del bienestar en Europa, Madrid, Escuela Libre Editorial/Civitas.

Barro, R. (1991): Economic growth in a cross-section of countries, The Quarterly Journal of Economics, vol. 106, $\mathrm{N}^{\circ} 2$, Cambridge, Massachusetts, The MIT Press, mayo.

Barro, R. y J.W. Lee (1993): International comparisons of educational attainment, Journal of Monetary Economics, vol. 32, $\mathrm{N}^{\mathrm{o}}$ 3, Amsterdam, Elsevier.

(1994): Sources of economic growth, Carnegie-Rochester Conference Series on Public Policy, vol. 40, Amsterdam, Elsevier.

(1996): International measures of schooling years and schooling quality, The American Economic Review, vol. 86, $\mathrm{N}^{\circ}$ 2, Nashville, Tennessee, American Economic Association.

(2001): International data on educational attainment updates and implications, Oxford Economic Papers, vol. 53, $\mathrm{N}^{\mathrm{o}} 3$, Oxford, Reino Unido, Oxford University Press.

Becker, G.S. (1962): Investment in human capital: a theoretical analysis, The Journal of Political Economy, vol. 70, $\mathrm{N}^{\circ} 5$, parte 2, Chicago, The University of Chicago Press.

(1964): Human Capital: A Theoretical and Empirical Analysis, with Special Reference to Education, primera edición, Nueva York, National Bureau of Economic Research.

(1975): Human Capital: A Theoretical and Empirical Analysis, with Special Reference to Education, segunda edición, Nueva York, National Bureau of Economic Research.

(1993): Human Capital: A Theoretical and Empirical Analysis, with Special Reference to Education, tercera edición, Nueva York, National Bureau of Economic Research.

Becker, G., K. Murphy y R. Tamura (1990): Human capital, fertility and economic growth, The Journal of Political Economy, vol. 98, Chicago, Illinois, The University of Chicago Press.

Behrman, J.R. y P. Taubman (1986): Birth order, schooling, and earnings, The Journal of Labor Economics, vol. 4, $\mathrm{N}^{\circ} 3$, parte 2, Chicago, Illinois, The University of Chicago Press.

Benhabib, J. y M. Spiegel (1994): The role of human capital in economic development: evidence from aggregate crosscountry data, Journal of Monetary Economics, vol. 34, $\mathrm{N}^{\circ} 2$, Amsterdam, Elsevier.

(1997): Cross-country Growth Regressions, Working Paper, N$^{\circ}$ 97-20, Nueva York, CV Starr Center for Applied Economics, Universidad de Nueva York.

Coombs, P. y M. Ahmed (1974): Attacking Rural Poverty. How Nonformal Education Can Help, Baltimore, John Hopkins University Press.

Coombs, P., C. Prosser y M. Ahmed (1973): New Paths to Learning for Rural Children and Youth, Nueva York, Consejo Internacional para el Desarrollo de la Educación.

De la Fuente, A. y J.M. da Rocha (1996): Capital humano y crecimiento: un panorama de la evidencia empírica y algunos resultados para la OCDE, Moneda y crédito, $\mathrm{N}^{\mathrm{o}} 203$, Madrid, Fundación Santander Central Hispano.
De la Fuente, A. y R. Doménech (2001): Schooling data, technological diffusion and the neoclassical model, The American Economic Review, vol. 91, No 2, Nashville, Tennessee, American Economic Association.

Denison, E. (1962): Sources of Economic Growth in the United States and the Alternatives Before Us, Nueva York, Committee for Economic Development.

(1964): Measuring the contribution of education (and the residual) to economic growth, The Residual Factor and Economic Growth, París, Organización de Cooperación y Desarrollo Económicos (OCDE).

Echevarría, C. (2004): Life expectancy, retirement and endogenous growth, Economic Modelling, vol. 21, № 1, Amsterdam, Elsevier

Foley, G. (1999): Learning in Social Action. A Contribution to Understanding Informal Education, Londres, NIACE/Zed Books.

Greenwood, J. y M. Yorukoglu (1997): 1974, Carnegie-Rochester Conference Series on Public Policy, vol. 46, Amsterdam, Elsevier.

Hanushek, E.A. (1992): The trade-off between child quantity and quality, The Journal of Political Economy, vol. 100, $\mathrm{N}^{\mathrm{o}} 1$, Chicago, Illinois, The University of Chicago Press.

Kalemli-Ozcan, S., H. Ryder y D. Weil (2000): Mortality decline, human capital investment, and economic growth, Journal of Development Economics, vol. 62, № 1, Amsterdam, Elsevier.

King, R. y S. Rebelo (1990): Public policy and economic growth: developing neoclassical implications, Journal of Political Economy, vol. 98, $\mathrm{N}^{\circ}$ 5, parte 2, Chicago, Illinois, The University of Chicago Press.

Krueger, A.B. y M. Lindahl (1999): Education for growth in Sweden and the world, Swedish Economic Policy Review, vol. 6, $\mathrm{N}^{\mathrm{o}} 2$, Estocolmo, The Economic Council.

Kyriacou, G. (1992): Level and Growth Effects of Human Capital: A Cross-country Study of the Convergence Hypothesis, Working Paper, No 91-26, Nueva York, CV Starr Center for Aplied Economics, Universidad de Nueva York.

Lam, D. y S. Duryea (1999): Effects of schooling on fertility, labor supply and investments in children, with evidence from Brazil, The Journal of Human Resources, vol. 34, No 1, Madison, Wisconsin, The University of Wisconsin Press.

Laroche, M., M. Merette y G.C. Ruggeri (1999): On the concept and dimensions of human capital in a knowledge-based economy context, Canadian Public Policy, vol. 25, $\mathrm{N}^{\mathrm{o}} 1$, Calgary, Alberta, Universidad de Calgary.

Leadbeater, C. (2000): Living on Thin Air. The New Economy, Londres, Penguin.

Levine, R. y D. Renelt (1992): A sensitivity analysis of cross-country growth regressions, The American Economic Review, vol. 82, $\mathrm{N}^{\circ}$ 4, Nashville, Tennessee, American Economic Association, septiembre.

Lucas, R. (1988): On the mechanics of economic development, Journal of Monetary Economics, vol. 22, № 1, Amsterdam, Elsevier.

(1993): Making a miracle, Econometrica, vol. 61, No 2, Evanston, Illinois, The Econometric Society, marzo.

Mankiw, N.G., D. Romer y D. Weil (1992): A contribution to the empirics of economic growth, The Quarterly Journal of Economics, vol. 107, № 2, Cambridge, Massachusetts, The MIT Press, mayo.

Meltzer, D. (1995): Mortality Decline, the Demographic Transition and Economic Growth, Cambridge, Massachusetts, Brigham and Women's Hospital/National Bureau of Economic Research, inédito.

Mingat, A. y J. Tan (1996): The Full Social Returns to Education: Estimates Based on Countries' Economic Growth Performance, Human Capital Development Working Papers, $\mathrm{N}^{\circ} 73$, Washington, D.C., Banco Mundial. 
Moav, O. (2005): Cheap children and the persistence of poverty, The Economic Journal, vol. 115, N ${ }^{\circ}$ 500, Oxford, Reino Unido, Blackwell Publishing.

Mushkin, S. (1962): Health and investment, The Journal of Political Economy, vol. 70, № 5, Chicago, Illinois, The University of Chicago Press.

OCDE (Organización de Cooperación y Desarrollo Económicos) (1999): Human Capital Investment. An International Comparison, París.

Parente, S. (1994): Technology adoption, learning-by-doing, and economic growth, Journal of Economic Theory, vol. 63, $\mathrm{N}^{\mathrm{o}} 2$, Amsterdam, Elsevier.

Rebelo, S. (1991): Long-run policy analysis and long-run growth, The Journal of Political Economy, vol. 99, № 3, Chicago, Illinois, The University of Chicago Press, junio.

Rodríguez, F. y J. Sachs (1999): Why do resource-abundant economies grow more slowly?, Journal of Economic Growth, vol. 4, Norwell, Massachusetts, Springer.

Romer, P. (1986): Increasing returns and long-run growth, The Journal of Political Economy, vol. 94, № 5, Chicago, Illinois, The University of Chicago Press, octubre.

(1990): Endogenous technological change, The Journal of Political Economy, vol. 98, $\mathrm{N}^{\circ}$ 5, parte 2, Chicago, Illinois, The University of Chicago Press, octubre.

Rosenzweig, M. y K. Wolpin (1980): Testing the quantity-quality fertility model: the use of twins as a natural experiment, Econometrica, vol. 48, $\mathrm{N}^{\circ}$ 1, Evanston, Illinois, The Econometric Society.

Ruggeri, G.C. y W. Yu (2000): On the dimensions of human capital: an analytical framework, Atlantic Canada Economics Association Papers, vol. 29, Sackville, New Brunswick.
Schultz, T. (1960): Capital formation by education, The Journal of Political Economy, vol. 69, Chicago, Illinois, The University of Chicago Press.

(1961): Investment in human capital, The American Economic Review, vol. 51, $\mathrm{N}^{\circ} 1$, Nashville, Tennessee, American Economic Association.

(1962): Reflections on investment in man, The Journal of Political Economy, vol. 70, Chicago, Illinois, The University of Chicago Press.

Silverman, B.W. (1986): Density Estimation for Statistics and Data Analysis, Londres, Chapman and Hall.

Smith, A. (1904): An Inquiry into the Nature and Causes of the Wealth of Nations, quinta edición, Londres, Methuen and Co., Ltd., ed. Edwin Cannan. Publicado originalmente en 1776.

Stokey, N. (1991): Human capital, product quality and growth, The Quarterly Journal of Economics, vol. 106, № 2, Cambridge, Massachusetts, The MIT Press.

Tamura, R. y M. Sadler (2001): Specialized Human Capital Investment, Growth and Convergence, Clemson, Clemson University, inédito.

Tight, M. (1996), Key Concepts in Adult Education and Training, Routledge, Londres.

Torres, C.A. (1990): The Politics of Nonformal Education in Latin America, Nueva York, Praeger Publishers.

Young, A. (1991): Learning-by-doing and the dynamic effects of international trade, The Quarterly Journal of Economics, vol. 106, $\mathrm{N}^{\mathrm{o}} 2$, Cambridge, Massachusetts, The MIT Press.

Youngman, F. (2000): The Political Economy of Adult Education, Londres, Zed Books.

Yu, W. (2001): A Survey of Existing Indicators for Human Capital, Ottawa, National Round Table on the Environment and the Economy. 